Nat. Hazards Earth Syst. Sci., 19, 1129-1149, 2019

https://doi.org/10.5194/nhess-19-1129-2019

(C) Author(s) 2019. This work is distributed under

the Creative Commons Attribution 4.0 License.

\title{
Analysis of an extreme weather event in a hyper-arid region using WRF-Hydro coupling, station, and satellite data
}

\author{
Youssef Wehbe $^{1,2}$, Marouane Temimi ${ }^{1}$, Michael Weston ${ }^{1}$, Naira Chaouch ${ }^{3}$, Oliver Branch ${ }^{4}$, Thomas Schwitalla ${ }^{4}$, \\ Volker Wulfmeyer ${ }^{4}$, Xiwu Zhan ${ }^{5}$, Jicheng Liu ${ }^{5,6}$, and Abdulla Al Mandous ${ }^{2}$ \\ ${ }^{1}$ Department of Civil Infrastructure and Environmental Engineering, Khalifa University of Science and Technology, \\ Masdar City, P.O. Box 54224 Abu Dhabi, United Arab Emirates \\ ${ }^{2}$ National Center of Meteorology (NCM), P.O. Box 4815, Abu Dhabi, United Arab Emirates \\ ${ }^{3}$ NOAA CREST Institute, City University of New York, 160 Convent Avenue, New York, NY 10031, USA \\ ${ }^{4}$ Institute of Physics and Meteorology, University of Hohenheim, Garbenstraße 30, 70599 Stuttgart, Germany \\ ${ }^{5}$ NOAA-NESDIS Center for Satellite Applications and Research (STAR), 5830 University Research Court \\ College Park, MD 20740, USA \\ ${ }^{6}$ ESSIC/CICS, University of Maryland College Park, College Park, MD 20740, USA
}

Correspondence: Youssef Wehbe (ywehbe@ncms.ae)

Received: 29 July 2018 - Discussion started: 11 September 2018

Revised: 5 May 2019 - Accepted: 13 May 2019 - Published: 13 June 2019

\begin{abstract}
This study investigates an extreme weather event that impacted the United Arab Emirates (UAE) in March 2016, using the Weather Research and Forecasting (WRF) model version 3.7.1 coupled with its hydrological modeling extension package (WRF-Hydro). Six-hourly forecasted forcing records at $0.5^{\circ}$ spatial resolution, obtained from the National Center for Environmental Prediction (NCEP) Global Forecast System (GFS), are used to drive the three nested downscaling domains of both standalone WRF and coupled WRF-WRF-Hydro configurations for the recent flood-triggering storm. Ground and satellite observations over the UAE are employed to validate the model results. The model performance was assessed using precipitation from the Global Precipitation Measurement (GPM) mission (30 min, $0.1^{\circ}$ product), soil moisture from the Advanced Microwave Scanning Radiometer 2 (AMSR2; daily, 0.1 product) and the NOAA Soil Moisture Operational Products System (SMOPS; 6-hourly, $0.25^{\circ}$ product), and cloud fraction retrievals from the Moderate Resolution Imaging Spectroradiometer Atmosphere product (MODATM; daily, $5 \mathrm{~km}$ product). The Pearson correlation coefficient (PCC), relative bias (rBIAS), and root-mean-square error (RMSE) are used as performance measures. Results show reductions of $24 \%$ and $13 \%$ in RMSE and rBIAS measures, respectively, in precipitation forecasts from the coupled WRF-WRF-Hydro
\end{abstract}

model configuration, when compared to standalone WRF. The coupled system also shows improvements in global radiation forecasts, with reductions of $45 \%$ and $12 \%$ for RMSE and rBIAS, respectively. Moreover, WRF-Hydro was able to simulate the spatial distribution of soil moisture reasonably well across the study domain when compared to AMSR2derived soil moisture estimates, despite a noticeable dry and wet bias in areas where soil moisture is high and low. Temporal and spatial variabilities of simulated soil moisture compare well to estimates from the NOAA SMOPS product, which indicates the model's capability to simulate surface drainage. Finally, the coupled model showed a shallower planetary boundary layer (PBL) compared to the standalone WRF simulation, which is attributed to the effect of soil moisture feedback. The demonstrated improvement, at the local scale, implies that WRF-Hydro coupling may enhance hydrological and meteorological forecasts in hyper-arid environments. 


\section{Introduction}

Changes in rainfall patterns directly impact hydrological processes overall and impact particularly the timing and magnitude of floods. In order to produce reliable flash flood warnings, accurate predictions of precipitation timings and amounts, along with their impact on resulting runoff, are needed. However, discrepancies are largely reported when forecasting precipitation using numerical weather prediction (NWP) models. The inaccurate predictions are then magnified in flood forecasts when simulated rainfall is used to drive a hydrological model (Wang and Seaman, 1997; NielsenGammon et al., 2005; Yousef and Ouarda, 2015). Standard hydrological models are often driven by precipitation products inferred from radar, rain gauge, and remote sensing observations, or a combination of them. The lack of dense radar and rain gauge networks in areas like the Arabian peninsula makes the reliance on precipitation remote sensing more attractive. However, such products come with coarse spatial resolution and fail to capture rainfall structures forced by mesoscale orography and land surface interactions, which are prevalent across the Arabian peninsula, including the UAE (Mandoos, 2006). A number of studies reported higher inaccuracies of precipitation products in arid regions (Fekete et al., 2004; Milewski et al., 2015; Wehbe et al., 2017, 2018), which suggests the interest in enhancing mesoscale modeling of weather processes in such regions to generate reliable precipitation products, and therefore accurate predictions of extreme hydrometeorological events. The Weather Research and Forecasting (WRF) model is a mesoscale NWP system created for the dual purpose of assisting with the needs of operational forecasting and facilitating atmospheric research. WRF is designed to be a next-generation mesoscale forecast model and data assimilation system for the purpose of advancing the understanding and prediction of mesoscale weather, and accelerating the transfer of research advances into operations (Skamarock et al., 2005). Powers et al. (2017) give a detailed overview of the initial phases of the WRF project.

A limited number of studies utilizing the WRF model focused on areas in the Middle East region. Awad et al. (2007) summarize the achievements of the UAE Air Force and Air Defense in the use of the WRF model, where a local operational suite was developed for predicting weather numerically over the Middle East region generally, and specifically over the Arabian peninsula and UAE areas. Recently, Chaouch et al. (2017) studied the consistency of WRF simulations with seven different planetary boundary layer (PBL) schemes and showed that a better performance is obtained with the quasi-normal scale elimination (QNSEEDMF) scheme while the remaining schemes showed a comparable performance. El Afandi et al. (2013) simulated heavy rainfall events in the Sinai Peninsula using WRF for the purpose of exploring how early warnings could be issued for flash flood risk mitigation. They found WRF simulations of a flash flood event on 18 January 2010 consistent with measurements recorded at rainfall gauges for different parts of the peninsula with RMSE values below $5 \%$.

The enhanced WRF Hydrological modeling extension package (WRF-Hydro) has shown improvement in prediction capabilities of hydrometeorological forecasts using numerical prediction tools when tested over other regions with climate conditions different from those observed in the Middle East (Parodi et al., 2013). It has been used for flash flood prediction, land-atmosphere coupling studies, regional hydroclimate impacts assessment, and seasonal forecasting of water resources (Gochis et al., 2013). Flash flood predictions using the WRF-Hydro model have been applied across the United States of America (Unal, 2015; Gochis et al., 2015; Read, 2015) and various parts of the world. Fiori et al. (2014) analyzed a convective system responsible for an extreme flash flood event that occurred in Genoa, Italy, on 4 November 2011, using WRF coupled with WRF-Hydro. The study outlined the effectiveness of the model in predicting quantitative precipitation for the purpose of flash flood forecasting. Streamflow forecasting from the fully coupled WRF-Hydro modeling system was evaluated through comparisons with both observations and uncoupled hydrological model results. The results of the study highlighted the need to consider multiple factors and sources of error for the prediction of hydrometeorological events, and it presented optimal configurations of WRF-Hydro for future extreme flash flood events in the Mediterranean region. A study conducted for the western Black Sea region of northern Turkey by Yucel et al. (2015) also analyzed the potential of the WRF-Hydro modeling system for flash flood predictions. The study explored the potential of improving runoff and streamflow simulations through the application of data assimilation for precipitation prediction in NWP models. The analyses involved concentrated on assessing the capabilities of the WRF and WRF-Hydro models in forecasting the responses of floods for the vast range of hydrological settings associated with 10 different events that occurred in the study area. Precipitation inputs for the forcing of the WRF-Hydro model were derived from the WRF model and the European Organisation for the Exploitation of Meteorological Satellites (EUMETSAT) multi-sensor precipitation estimates (MPEs). The use of a data assimilation scheme with the WRF model provided significant improvements in simulations of streamflow, while the MPE product led to less accurate streamflow simulations. The optimum results in error reduction were obtained when both WRF model data assimilation and hydrological model calibration were employed.

In a recent study, Givati et al. (2016) calibrated and evaluated the coupled WRF-WRF-Hydro modeling system with the standalone WRF model for flood forecasting of Wadi Musrara, Israel, for two major winter storm events in January and December 2013. Higher correlations (0.89 and 0.85 ) with the station observations were recorded by the coupled WRF-Hydro model than those of the standalone WRF 
model (0.85 and 0.80) for both events. Lower RMSE values were also obtained by the coupling (12.2 and 24 compared to 16 and 30). The findings of the study showed that the coupled WRF-WRF-Hydro modeling system resulted in improved precipitation and hydrological simulations when compared with the results of the standalone WRF simulations. Therefore, the authors proposed the employment of atmospheric-hydrological coupling due to its potential to produce improved precipitation predictions, which translates to better hydrological forecasts for early flood hazard mitigation. The application of WRF-Hydro for flood forecasting in arid environments has also been explored by Silver et al. (2017). They simulated six storm events over seven basins in arid and semi-arid regions of Israel and Jordan using WRF-Hydro while incorporating field-based soil characterization data into the land surface model initialization. NashSutcliffe efficiency coefficient (NSE) values of up to 0.415 were recorded between the observed streamflow records and WRF-Hydro simulated streamflow. In desert regions, high soil porosity and hydraulic conductivity of the prevailing sandy soil implies rapid infiltration and runoff drainage. This suggests that the impact on latent heat and, therefore, on the surface radiation budget would be minimal. Alternatively, precipitation largely contributes to soil physical crust formation in desert environments (Fang et al., 2007). Precipitation compacts fine particulate and fills the pores of the top soil layer, forming a hard shell. Dust is also washed out of the atmosphere by precipitation over desert environments which increases amounts of finer particulate at the surface layer to further accelerate the crust formation process. This translates to less vertical infiltration and more lateral flow processes. These mechanisms are specific to arid regions and corroborate the importance of accounting for lateral flow and surface feedback in the coupled WRF-WRF-Hydro model to correctly capture the atmospheric and hydrological process.

The present study expands the ongoing research addressing the prediction of extreme hydrometeorological events in arid regions and investigates the potential of coupling atmospheric and hydrological processes in short-term prediction. There is interest in determining the potential improvement in the simulation that the online land-atmosphere coupling could bring in the case of an extreme hydrometeorological event. To our knowledge, such coupling has never been assessed in hyper-arid environments like the one observed in the UAE where hydrological and atmospheric processes are specific and different from other study domains where similar coupling was evaluated. We focus in this study on an extreme hydrometeorological event recorded on 9 March 2016 over the UAE. The standalone WRF and fully coupled WRFWRF-Hydro simulations are assessed against (i) weather station surface observations of rainfall, $2 \mathrm{~m}$ surface temperature and global radiation, and (ii) satellite remote sensing retrievals of Global Precipitation Measurement (GPM) rainfall, the Advanced Microwave Scanning Radiometer 2 (AMSR2)derived soil moisture, and the Moderate Resolution Imaging
Spectroradiometer Atmosphere product (MODATM) cloud fraction. In the absence of ground-based streamflow gauges in the study domain, satellite data were valuable to understand the dynamics of the event and changes in precipitation, and soil moisture distributions.

\section{Study domain and datasets}

\subsection{Case study}

This study consists of three nested domains (see Fig. 1), with the parent domain covering the Arabian peninsula, Iran, Iraq, Afghanistan, and parts of Pakistan, Syria, and Ethiopia (9 to $37^{\circ} \mathrm{N}$ and 39 to $70^{\circ} \mathrm{E}$ ), thus capturing a broad range of weather systems. The UAE ( 22 to $27^{\circ} \mathrm{N}$ ) is part of the arid climatic regime of the Arabian peninsula, characterized by high temperatures and dry environment during summers and mild wet winters. The region is located in two distinct climate zones: subtropical north of $20^{\circ} \mathrm{N}$ and the tropical or monsoonal southern part (AlSarmi and Washington, 2011; Almazroui et al., 2012). Winter and early spring occur from January to April. During this period the region is affected by the Siberian High pressure with cold air mass and the Red Sea trough (RST) in the northern and southern parts of the peninsula, respectively (Tsvieli and Zangvil, 2007). The summer season extends from June to August and is greatly impacted by the Indian monsoon depression. The monsoon is associated with the low-level jet (LLJ) affecting the southern part of the peninsula (Sathiyamoorthy et al., 2013). The Tropic of Cancer, located under the descending limb of the Hadley cell, leads to the region being dominated by subtropical anticyclones, associated with air subsidence, stable conditions, and high pressure (Mandoos, 2006).

Figure 1 also shows the high-resolution (100 m) WRFHydro terrain model domain over the UAE, along with the associated topography map derived from the $30 \mathrm{~m}$ resolution Advanced Spaceborne Thermal Emission and Reflection Radiometer (ASTER) digital elevation model (DEM) (Toutin, 2008). The Al Hajar Mountains, located along the Gulf and Oman coasts, foster local convergence zones that trigger small-scale convection initiation (Chaouch et al., 2017). Consequently, the northeastern part of the UAE receives more rainfall compared to the country's $100 \mathrm{~mm}$ annual average (Ghebreyesus et al., 2016a, b; Ouarda et al., 2014; Wehbe et al., 2017). The inland city of $\mathrm{Al}$ Ain is of close proximity to the Al Hajar Mountains on the southerly downside, designating it as a susceptible area to flash floods triggered by accumulated upstream runoff from the northern highlands. Farming and agriculture is concentrated in this area to benefit from the oasis effects of high rainfall rates and fresh groundwater, compared to other parts of the country.

On 9 March 2016, a low pressure system passing from the UAE and Oman to southeastern Iran produced thunderstorms, fierce winds, large hail, and severe flooding. Accord- 


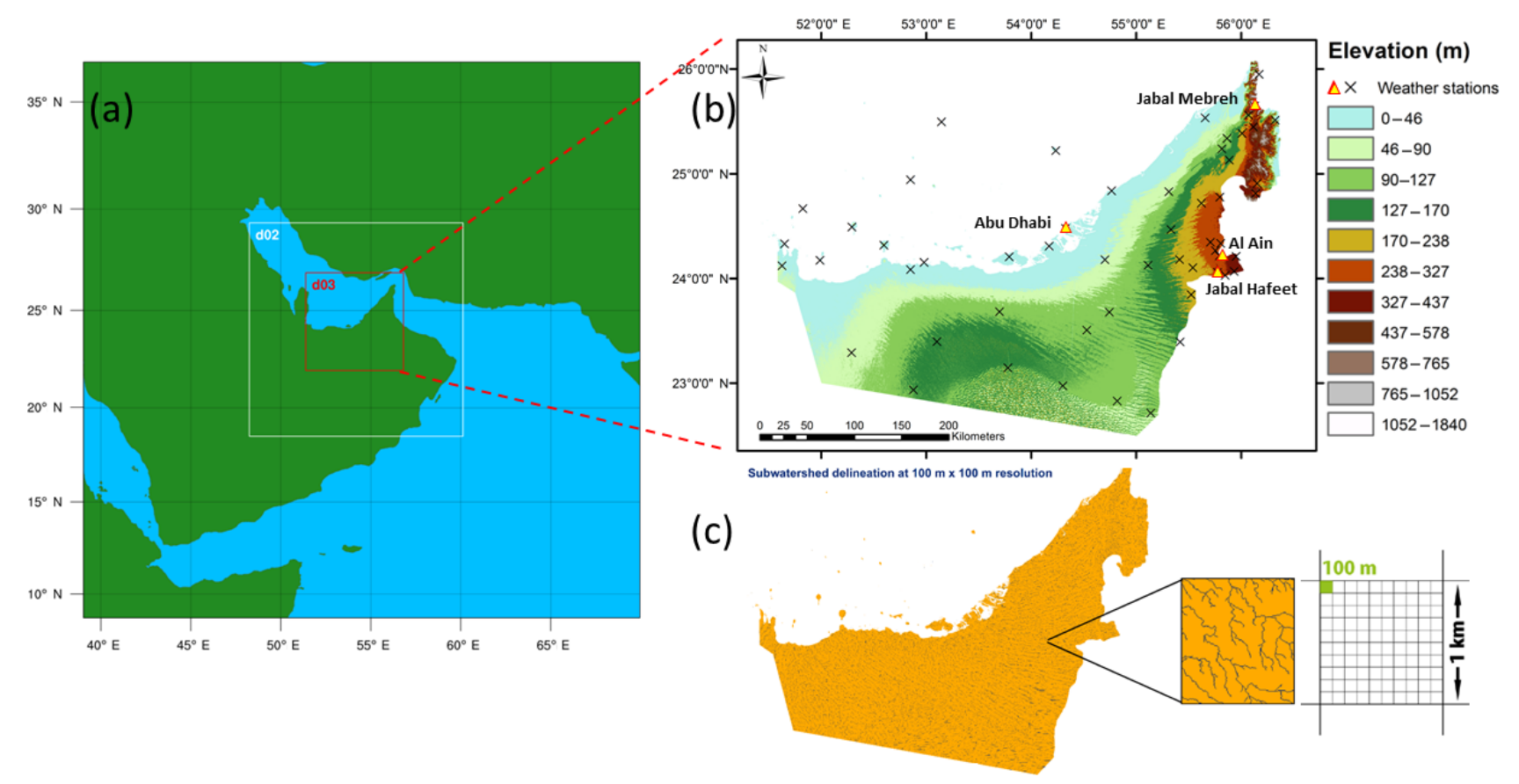

Figure 1. WRF model nested domains at 9, 3 (d02), and $1 \mathrm{~km}$ (d03) horizontal resolutions (a), $30 \mathrm{~m}$ ASTER DEM with station locations (b), and the $100 \mathrm{~m}$ WRF-Hydro grid derived over the UAE (a).

ing to the UAE National Center of Meteorology (NCM), over $240 \mathrm{~mm}$ of rain was recorded in Dubai while winds of up to $126 \mathrm{~km} \mathrm{~h}^{-1}$ battered the capital (Blašković, 2016). The movement of an Active Red Sea Trough, associated with hot and dry weather resulting from east-southeasterly flows in the lower troposphere, and accompanied by a cold uppertropospheric trough extending from the north, resulted in unstable stratification. Such stratification resulted in the development of a mesoscale convective system. The accumulation of clouds over the western side of the UAE developed and gradually moved towards the coastal areas. The influence of the southeasterly moist air contributed to the evolution of the clouds, so that their vertical extent exceeded $5 \mathrm{~km}$, according to radiosondes retrieved by the NCM at Abu Dhabi Airport. The resulting skew-T profiles are shown in Fig. 2 for 9 March 2016 at times 00:00 Z (a) and 12:00 Z (b). The temperature inversions in the surface layer $(80-761 \mathrm{~m}) \mathrm{de}-$ picted in Fig. 2a indicate the onset of the event with convective available potential energy (CAPE) values reaching 506.3. Figure $2 \mathrm{~b}$ shows the extent of the towering cumulus clouds from cloud bases of $770 \mathrm{~m}(920 \mathrm{hPa})$ at the lifting condensation level (LCL) to cloud tops at the divergence of the overlapping dew point and temperature profiles at the $6200 \mathrm{~m}$ $(530 \mathrm{hPa})$ level. The freezing level triggering the heavy rain event was reached above $4100 \mathrm{~m}$.

\subsection{Datasets}

Satellite and ground-based observations were used for the verification of WRF and WRF-Hydro simulations. In the case of the former, necessary data re-gridding were done to match WRF outputs spatially and temporally. The following datasets were used to quantitatively and qualitatively assess the performance of the simulations.

\subsubsection{The Global Precipitation Measurement (GPM) mission}

The simulated precipitation was compared to GPM satellite retrievals. The GPM mission, launched in February 2014, provides high temporal $(30 \mathrm{~min})$ and spatial $\left(0.1^{\circ}\right)$ resolution precipitation estimates through the Integrated Multi-satellitE Retrievals (IMERG) product. The GPM IMERG product inter-calibrates, merges, and interpolates GPM constellation satellite microwave precipitation estimates with microwavecalibrated infrared estimates, and rain gauge analyses to produce a higher resolution and more accurate product (Huffman et al., 2014). The GPM core satellite estimates precipitation from two instruments, the GPM microwave imager (GMI) and the dual-frequency precipitation radar (DPR). More importantly for this study, the GPM radar has been upgraded to two frequencies, adding sensitivity to light precipitation. 


\subsubsection{The Advanced Microwave Scanning Radiometer 2 (AMSR2)}

Soil moisture estimates from the AMSR2 mission were used to verify the simulated soil moisture and its simulated spatial extent. In this study we rely on AMSR2 datasets for the verification of simulated soil moisture as products from other datasets were masked out over the study area during the investigated event. AMSR2 was launched on 18 May 2012 on-board the Global Change Observation Mission 1st-Water (GCOM-W) platform, with the capability of measuring passive microwave emissions from the surface and atmosphere. The window channels on-board the sensor are capable of retrieving key surface parameters like soil moisture. AMSR2 L3 datasets provide daytime and nighttime soil moisture measurements with near-global coverage over $3 \mathrm{~d}$ (Wentz et al., 2014). Moreover, AMSR 2 is equipped with frequencies higher than the $\mathrm{L}$ band that are more suitable for soil moisture retrievals. Such frequencies, ranging from 6.93 to $89 \mathrm{GHz}$, are currently available on-board Soil Moisture and Ocean Salinity (SMOS) and Soil Moisture Active Passive (SMAP) missions.

\subsubsection{The MODIS Atmosphere product (MODATM)}

The MODATM dataset from Platnick et al. (2015) contains measurements in 36 spectral bands ( 250 to $1000 \mathrm{~m}$ resolution in nadir) for a combination of key atmospheric parameters at daily and 5 or $10 \mathrm{~km}$ resolutions (parameter dependent), including aerosol properties, water vapor profiles, and cloud properties, starting 13 October 2003 and are currently ongoing. The cloud mask is derived as a probabilistic variable from multispectral testing techniques proposed by Ackerman et al. (1998). The cloud fraction (10 km resolution), used in this study, is obtained from the Terra platform's infrared retrievals during both day and night.

\subsubsection{Weather stations}

Rainfall, surface temperature ( $2 \mathrm{~m})$, and average global radiation records were obtained from a network of 57 automatic weather stations (see Fig. 1) operated by the NCM across the UAE. Rainfall observations were recorded at $15 \mathrm{~min}$ intervals during the event, while hourly observations of temperature and global radiation were made available after quality control.

\section{Methodology}

Two simulations were carried out in this study: one with the standalone WRF version and another with the online coupled WRF-WRF-Hydro version. In both simulations, the initial and lateral boundary conditions of the parent domain were defined from the Global Operational Analysis and Forecast Products of the National Center for Environmental Predic- tion (NCEP-GFS) at $0.5^{\circ}$ spatial resolution and $6 \mathrm{~h}$ intervals (00:00, 06:00, 12:00, and 18:00 UTC). The static terrain attributes and topography used in the WRF preprocessing system (WPS) were derived from United States Geologic Survey (USGS) datasets (Smart et al., 2005). A description of the configuration of each version is in the following sections.

The existing Noah-multiparameterization land surface model (Noah-MP LSM) in the standalone WRF considers single vertical columns (one-dimensional) of terrain properties at each overland grid cell (Niu et al., 2011; Ek et al., 2003). It fails to account for horizontal interactions between adjacent grid cells to calculate soil moisture, temperature profiles, runoff, and water and energy fluxes at the land surface. Therefore, the runoff-infiltration partitioning in the standalone WRF simulation is described as a purely isolated vertical process with no intake from (or discharge to) neighboring grid cells, as dictated by topography. On the other hand, the WRF-Hydro model utilizes the Noah-MP LSM 1$D$ representations and attempts to improve the simulation of terrestrial hydrologic processes at high spatial and temporal resolutions by including lateral redistribution of overland and saturated subsurface flows for runoff prediction (Gochis et al., 2013). More importantly for this study, WRF-Hydro is run in coupled mode with WRF to permit the feedback of land surface fluxes of energy and moisture to the atmosphere, which impacts the simulated precipitation fields (Arnault et al., 2016; Larsen et al., 2016; Senatore et al., 2015; Koster et al., 2004). Hence, the coupled WRF-WRF-Hydro configuration differs from the standalone WRF configuration by its (i) lateral distribution of surface runoff and (ii) feedback of surface fluxes to the atmosphere.

\subsection{Standalone WRF}

The model configuration and $1: 3$ downscaling ratio was setup as recommended by Givati et al. (2011), consisting of three nested domains $-\mathrm{d} 01$ (parent domain) with a $350 \times 350$ grid of $9 \mathrm{~km}$ resolution; d02 (intermediate domain) with a $403 \times 403$ grid of $3 \mathrm{~km}$ resolution, and d03 (inner domain) with a $562 \times 562$ grid with $1 \mathrm{~km}$ spacing (see Fig. 1).

Based on the comparable performance of planetary boundary layer (PBL) schemes over the UAE (Chaouch et al., 2017) and given the unstable conditions during the event, the non-local Yonsei University (YSU) scheme is selected as the most favorable scheme for maintaining an entrainment flux proportional to the surface flux (Hariprasad et al., 2014; $\mathrm{Hu}$ et al., 2010; Shin and Hong, 2011). The selection of a microphysics scheme has been shown to be of least importance compared to PBL and cumulus schemes (Argüeso et al., 2011).

In light of the findings of Givati et al. (2011), the physics options chosen for this study included the following: the Noah-MP land surface scheme (Niu, 2011), MoninObukhov surface layer scheme (Monin and Obukhov, 1954), the rapid radiative transfer model for general circulation 
models (RRTMG) longwave (Mlawer et al., 1997) and shortwave radiation schemes (Iacono et al., 2008), and the Morrison double-moment cloud microphysics scheme (Morrison et al., 2009) with improved strati-formed cloud persistence compared to the single-moment scheme. The WRF and WRF-Hydro configurations are listed in Table 1.

\subsection{Coupled WRF-WRF-Hydro}

The WRF Hydrological modeling extension package (WRFHydro) from Gochis et al. (2013) was developed through research collaborations between the National Center for Atmospheric Research (NCAR) and its partners, the National Aeronautics and Space Administration (NASA), and the National Oceanic and Atmospheric Administration (NOAA). It can be used as a standalone model and has an architecture to facilitate coupling between hydrological models and atmospheric models. It provides the capability to spatially relate meteorological variables to physical and terrestrial attributes (elevation, soil, land use, etc.) and their associated feedbacks. Several hydrologic routing physics options exist in the version 3.0 of WRF-Hydro. Here, a fully distributed three-dimensional overland surface flow model configuration was employed. Soil moisture initialization was provided from the WPS along with the predefined soil hydraulic parameters for the Noah-MP LSM on the basis of USGS soil classifications (Ek et al., 2003).

The geographic information system (GIS) Python-based preprocessing approach from Gochis and Sampson (2015) was followed to derive the WRF-Hydro LSM and routing grids. Inputs of the static terrain properties from the WPS GEOGRID file and the high-resolution $(30 \mathrm{~m})$ ASTER DEM were used. A re-gridding factor of 10 was applied to reach the $100 \mathrm{~m}$ LSM resolution from the $1 \mathrm{~km}$ GEOGRID resolution. The minimum basin size was defined by a threshold of 20 pixels per stream, following the analytical method for stream network delineation proposed by Tarboton et al. (1991). Overall, a dominant parallel pattern of stream networks is obtained, draining water westward from the mountainous region in eastern UAE towards the western side of the Arabian Gulf (Fig. 1). The northern part of the UAE shows a large number of streams flowing in the opposite direction towards the eastern side of the country. The sandy nature of the soil in the desert in the southwestern side of the country favors rapid infiltration of runoff and its drainage towards the Gulf as groundwater, before it makes surface around the western coastal regions (Fig. 1). This contributes to the existence of salt flats around those regions. To our knowledge, a dense drainage network which may allow us to identify the main wadis in the western region does not exist in the UAE and this study proposes a first version of such a network. The challenge faced when studying hydrological processes in hyper-arid regions, like the UAE, is the absence of gauged watersheds and lack of in situ data to calibrate and verify hydrological models. In this study, the performance of the hydrological simulations was evaluated using satellite soil moisture data and the analysis of the changes in its lateral extent.

\subsection{Statistical performance measures}

The RMSE and rBIAS methods of evaluation were implemented, with the value observed representing the station measurement, or the satellite retrieval in the absence of a station observation (Eqs. 1 and 2). The RMSE and rBIAS reflect the average error and degree of over- or underestimation of the model output fields.

$\begin{aligned} \text { RMSE } & =\sqrt{\frac{\sum_{i=1}^{n}\left(y_{\mathrm{o} i}-y_{\mathrm{est} i}\right)^{2}}{n},} \\ \mathrm{rBIAS} & =\frac{\sum_{i=1}^{n}\left(y_{\mathrm{est} i}-y_{\mathrm{o} i}\right)}{\sum_{i=1}^{n} y_{\mathrm{o} i}} \times 100,\end{aligned}$

where $y_{\mathrm{est} i}$ and $y_{\mathrm{o} i}$ are the estimated (simulated) and observed values, respectively, at station $i$, and $n$ is the number of observations.

The Pearson correlation coefficient (PCC) (Benesty et al., 2009) was used in relating the observed values and model output (Eq. 3). The Pearson correlation reflects the statistical association between variables and can range between -1 to 1 , where 1 is total positive linear correlation, 0 is no linear correlation, and -1 is total negative linear correlation.

$\mathrm{PCC}=\frac{\sum_{i=1}^{n}\left(y_{\mathrm{o} i}-\bar{y}_{\mathrm{o}}\right)\left(y_{\mathrm{est} i}-\bar{y}_{\mathrm{est}}\right)}{\sqrt{\sum_{i=1}^{n}\left(y_{\mathrm{o} i}-\bar{y}_{\mathrm{o}}\right)^{2} \times \sum_{i=1}^{n}\left(y_{\mathrm{est} i}-\bar{y}_{\mathrm{est}}\right)^{2}}}$

\section{Results and discussion}

\subsection{Analyses of atmospheric variables}

\subsubsection{Gauge rainfall versus GPM, WRF, and WRF-WRF-Hydro}

Figure 3 shows the cumulative event rainfall over the UAE in $\mathrm{d} 03$ between $06: 00 \mathrm{Z}$ on 8 March 2016 and 06:00 Z on 10 March 2016. This includes values recorded by the rain gauges (a), values retrieved from the GPM product (b), and values simulated from the WRF and WRF-WRF-Hydro runs ( $c$ and $d$, respectively). The highest cumulative rainfall of $288 \mathrm{~mm}$ was recorded by the rain gauge at Al Shiweb weather station (see Fig. 3a) in the northeastern part of the UAE. Lower rainfall rates between 30 to $70 \mathrm{~mm}$ were recorded along the coast and western parts of the country. The minimum, maximum, and mean from each rainfall source are listed in Table 2, in addition to the correlation, RMSE, and rBIAS values of the simulated and GPMretrieved rainfalls against the station records over the UAE.

GPM retrievals recorded a maximum cumulative rainfall of $189 \mathrm{~mm}$ over the eastern coast of Oman which is lower 

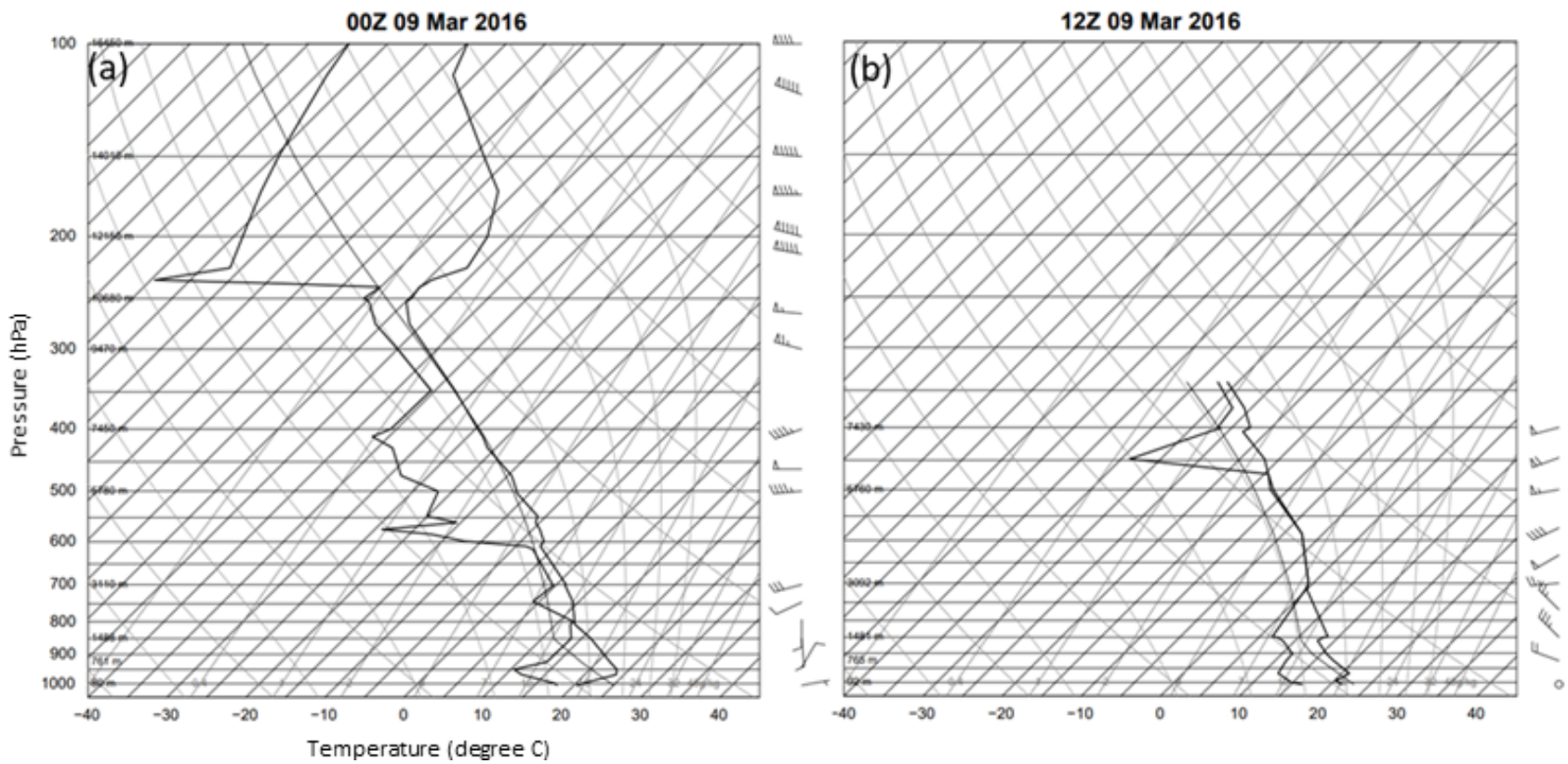

Figure 2. Radiosonde skew-T profiles retrieved at Abu Dhabi Airport on 9 March 2016 at 00:00Z (a) and 12:00Z (b).

Table 1. WRF and WRF-Hydro model configurations.

\begin{tabular}{ll}
\hline WRF and WPS version & $\begin{array}{l}\text { Version 3.7.1 released on } \\
14 \text { August } 2015 \text { with latest bug fixes }\end{array}$ \\
\hline WRF-Hydro version & Version 3.0 released on 14 June 2015 \\
\hline Domain horizontal resolutions & $9 \mathrm{~km}$ for d01 \\
$3 \mathrm{~km}$ for d02 \\
$1 \mathrm{~km}$ for d03 \\
$100 \mathrm{~m}$ for WRF-Hydro LSM \\
\hline Domains horizontal grid dimensions & $350 \times 350$ for d01 \\
& $403 \times 403$ for d02 \\
\hline Projection & $562 \times 562$ for d03 \\
\hline Number of vertical levels & Transverse Mercator \\
\hline Top Pressure value & 50 for each domain \\
\hline Lateral boundary conditions & $20 \mathrm{hPa}$ \\
\hline Initial conditions & GFS 6-hourly forecasts at $0.5^{\circ}$ \\
\hline Longwave and shortwave radiation & RRTMG \\
\hline Surface Layer & Monin-Obukhov \\
\hline Land surface model & Noah-MP \\
\hline Planetary boundary layer scheme & Yonsei University \\
\hline Microphysics & Morrison double-moment \\
\hline
\end{tabular}



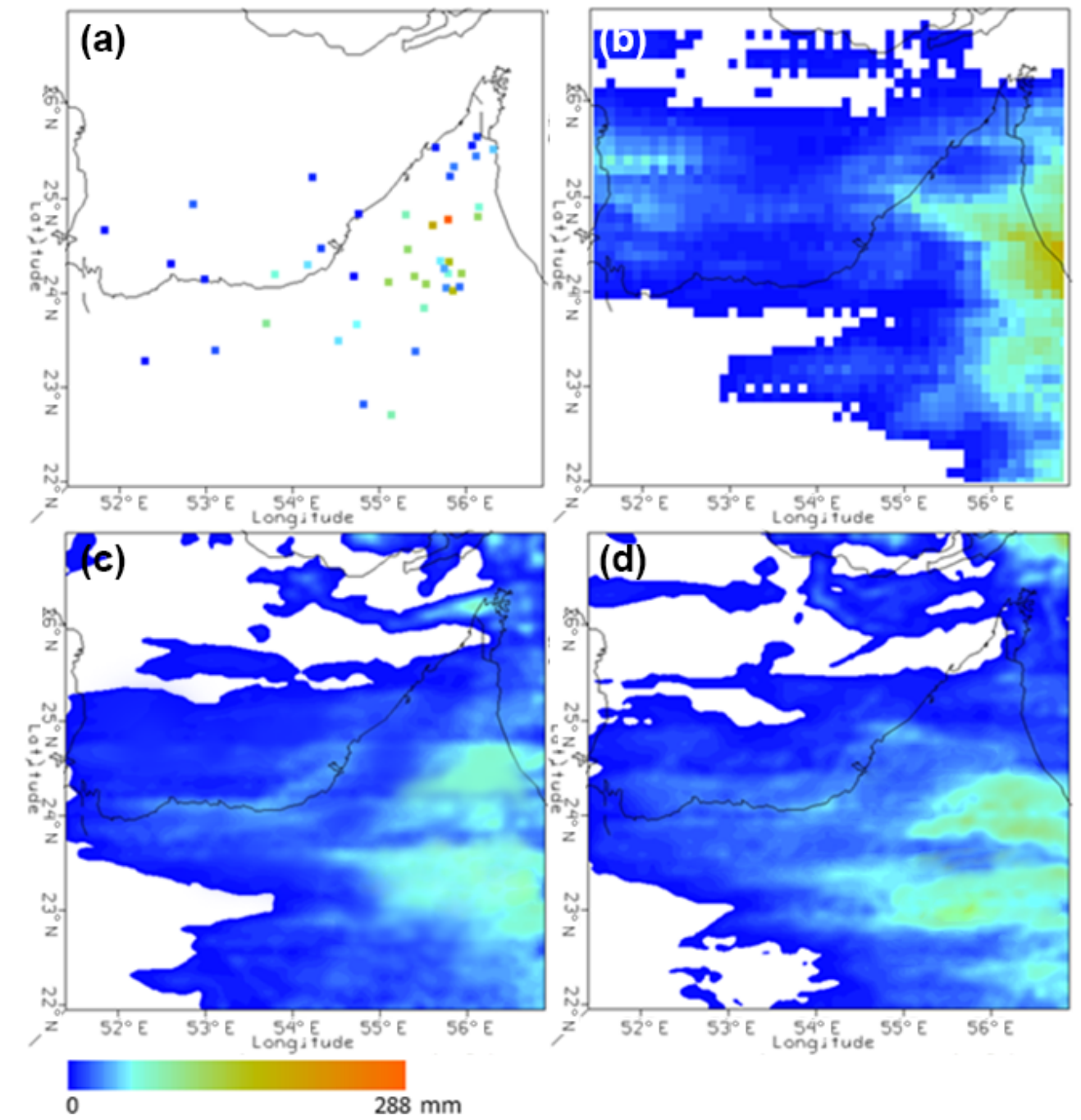

Figure 3. Accumulated storm rainfall over the UAE (d03) from station observations (a), GPM 30 min, $0.1^{\circ}$ retrievals (b), WRF (c), and WRF-WRF-Hydro (d).

Table 2. Total storm rainfall statistical measures from collocated GPM retrievals, station observations, and simulations (WRF and WRFWRF-Hydro).

\begin{tabular}{lrrrrrrr}
\hline Precipitation source & $\begin{array}{r}\text { Mean } \\
(\mathrm{mm})\end{array}$ & $\begin{array}{r}\text { Min. } \\
(\mathrm{mm})\end{array}$ & $\begin{array}{r}\text { Max. } \\
(\mathrm{mm})\end{array}$ & $\begin{array}{r}\text { Std. } \\
(\mathrm{mm})\end{array}$ & PCC & RMSE & rBIAS \\
\hline Station observations & 48 & 0.4 & 288 & 57 & & & \\
GPM retrievals & 47 & 0.03 & 189 & 55 & 0.89 & 6.12 & 0.71 \\
Coupled WRF-Hydro & 39 & 0.01 & 156 & 47 & 0.82 & 10.89 & 0.21 \\
Standalone WRF & 32 & 0.01 & 122 & 42 & 0.76 & 14.24 & 0.34 \\
\hline
\end{tabular}

than the maximum obtained from the station data in the UAE (readings in Oman are not available). This implies that GPM could have underestimated rainfall records as it did not capture the maximum cumulative reading reported at Al Shiweb weather station $(288 \mathrm{~mm})$. This could be explained by the lower temporal coverage of GPM (30 min) compared to the stations (15 $\mathrm{min})$, and this could have led to the former miss- ing the peak of rainfall records. Another reason that could explain the underestimation is the coarse spatial resolution of GPM data $(10 \mathrm{~km})$, which senses rainfall over a footprint larger than the one represented by the local rain gauge readings. On the other hand, GPM overestimates cumulative rainfall values ranging between 50 to $90 \mathrm{~mm}$ in the northeastern part of the UAE and highlands (see Fig. 3b). Minimum rain- 
falls between 10 to $40 \mathrm{~mm}$ were recorded by stations along the western coast lines and central inlands, while no significant rainfall was recorded over the western areas. In a study that validated a number of precipitation products over UAE for a 10-year period (Wehbe et al., 2017), it was shown that the analyzed remote sensing products perform better at higher elevations $(>250 \mathrm{~m})$, which is the case of Al Shiweb weather station $(306 \mathrm{~m})$. In line with the previous study, the lowland stations in the western region showed higher biases by GPM and retrievals over areas not receiving any rainfall during the event. More events are needed to accurately assess the performance of GPM in the region and demonstrate any potential improvement over its predecessor, Tropical Rainfall Measurement Mission (TRMM) (Huffman et al., 2007), among others.

The standalone WRF and fully coupled WRF-WRFHydro simulated rainfall exhibited spatial rainfall patterns similar to those obtained from GPM and station data, with the highest rainfall simulated over the coast of Oman and eastern UAE (see Fig. 3c and d). However, the coupled WRF-WRFHydro model resulted in a maximum cumulative rainfall of $156 \mathrm{~mm}$ over the northeastern border with Oman, which is closer to the $189 \mathrm{~mm}$ obtained from GPM readings compared to the $122 \mathrm{~mm}$ from the standalone WRF system. Also, more rainfall was reproduced over the western quarter by the standalone WRF than by the coupled WRF-WRF-Hydro where GPM and stations do not report significant readings. Overall, more of the rainfall retrieved by GPM or measured by the stations was reproduced by the coupled WRF-WRF-Hydro model, and a better agreement in the spatial pattern of rainfall and its magnitude is obtained.

More importantly, the lowest rBIAS (0.21) was obtained from the WRF-WRF-Hydro setup, followed by the WRF setup (0.34), and the GPM retrievals (0.71). The higher bias associated with the GPM rainfall retrievals is thought to be related to the difference in spatial scales, ice-scattering microwave retrieval mechanism, and locality of orographic rainfall events, among other factors. The improved performance of the coupled WRF-WRF-Hydro system compared to the standalone WRF is evident across all measures in Table 2 - closer to the observed $48 \mathrm{~mm}$ mean and $288 \mathrm{~mm}$ maximum ( 39 vs. $32 \mathrm{~mm}$ and 156 vs. $122 \mathrm{~mm}$ ), higher correlation (0.82 vs. 0.76$)$, and lower RMSE (10.89 vs. 14.24) and rBIAS (0.21 vs. 0.34$)$. The resulting coupling improvements translate into a $24 \%$ and a $13 \%$ decrease in RMSE and rBIAS, respectively. The enhanced precipitation forecast will directly impact land surface processes. The degree of improvement achieved here is in line with the findings of Givati et al. (2016) over the Ayalon basin in Israel during a 1-month simulation of WRF versus WRF-WRF-Hydro, in which they recorded a $21 \%$ decrease in the coupled precipitation RMSE. Figure 4 shows the observed, simulated (WRF and WRFWRF-Hydro), and GPM-retrieved cumulative rainfall during the event at four selected stations, namely, the coastal Abu Dhabi station (Fig. 4a), inland Al Ain station (Fig. 4b),
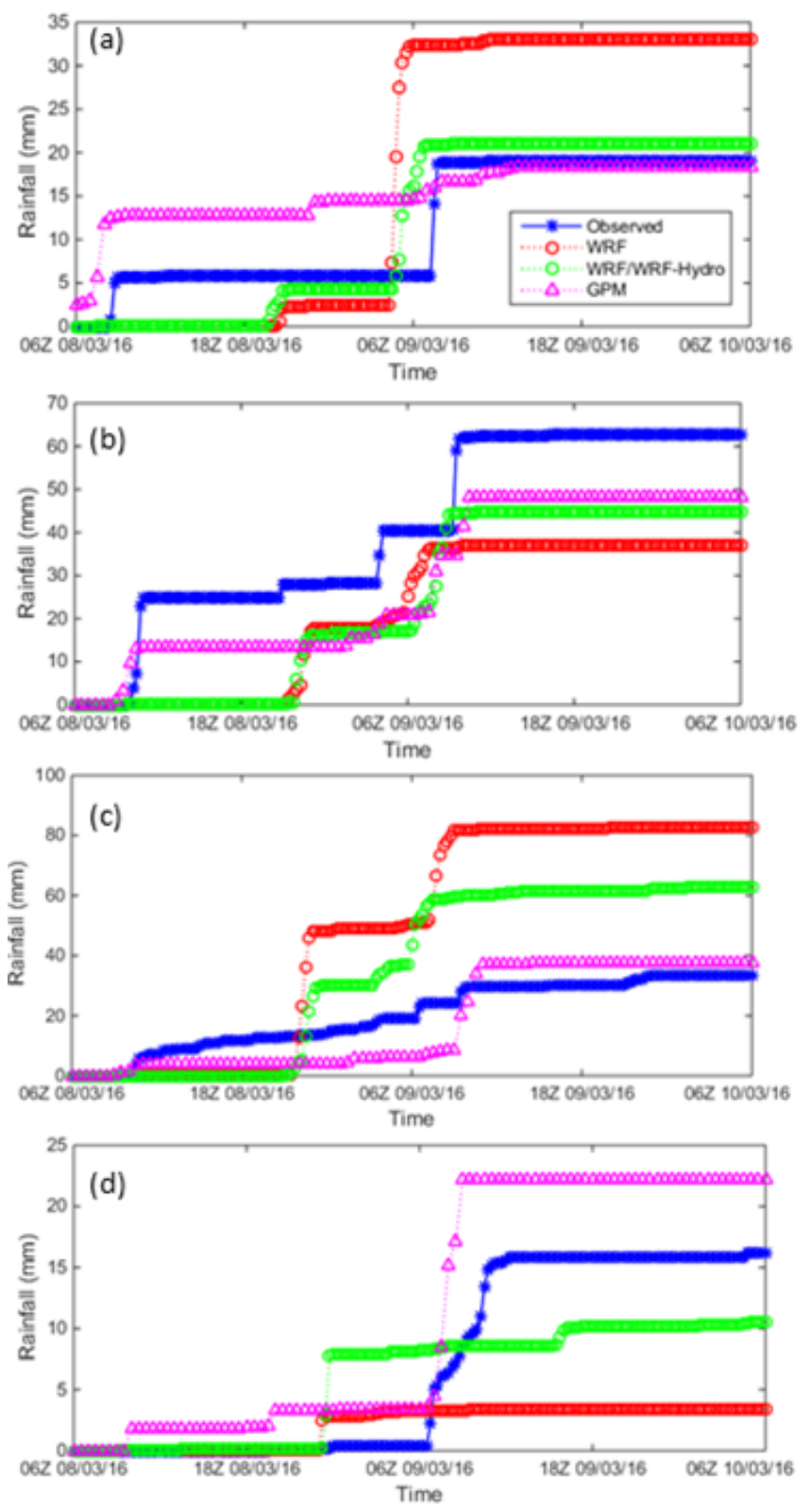

Figure 4. Comparison of accumulated rainfall at Abu Dhabi (a), Al Ain (b), Jabal Hafeet (c), and Jabal Mebreh (d) from stations with WRF, WRF-WRF-Hydro simulations, and GPM retrievals.

and mountainous Jabal Hafeet (Fig. 4c) and the Jabal Mebreh (Fig. 4d) stations situated on the northeastern highlands at altitudes of 1080 and $1433 \mathrm{~m}$ (see Fig. 1), respectively. The stations were selected to capture the spatial variability of the rainfall across the study domain as well as the potential impact of the topography with stations located at flat open terrain and others at higher altitude. In Fig. 4, time intervals of $15 \mathrm{~min}$ were used to derive the cumulative plots, while 30 min intervals were available for the GPM product.

Table 3 summarizes the error measures at each station. In all four cases, the simulated WRF rainfall recorded the 
Table 3. RMSE (rBIAS) of simulated and retrieved rainfall at Abu Dhabi, Al Ain, Jabal Hafeet, and Jabal Mebreh stations for 30 min intervals $(n=97)$.

\begin{tabular}{lrrr}
\hline Station & WRF & WRF-WRF-Hydro & GPM \\
\hline Abu Dhabi & 1.36 & 0.90 & 1.10 \\
& $(0.84)$ & $(0.11)$ & $(0.74)$ \\
\hline Al Ain & 2.11 & 2.03 & 2.49 \\
& $(-0.41)$ & $(-0.28)$ & $(0.22)$ \\
\hline Jabal Hafeet & 1.92 & 1.29 & 1.46 \\
& $(1.46)$ & $(0.92)$ & $(0.86)$ \\
\hline Jabal Mebreh & 0.52 & 0.38 & 0.96 \\
& $(-0.79)$ & $(-0.35)$ & $(1.53)$ \\
\hline
\end{tabular}

poorest performance and highest deviations (underestimation and overestimation) from the observed rainfall pattern with rBIAS values of $0.84,-0.41,1.46$, and -0.79 at Abu Dhabi, Al Ain, Jabal Hafeet, and Jabal Mebreh stations, respectively. GPM recorded overestimations across all four stations with rBIAS measures of $0.74,0.22,0.86$, and 1.53 at stations of Abu Dhabi, Al Ain, Jabal Hafeet, and Jabal Mebreh, respectively. Both models show a 4 to $6 \mathrm{~h}$ latency in rainfall initiation between 18:00 Z on 8 March 2016 and 23:00 Z on 8 March 2016. However, after the initiation phase, the WRF-Hydro system follows the observed patterns more closely, while outperforming (in terms of RMSE and rBIAS) the GPM pattern at the stations of Abu Dhabi ( 0.9 and 0.11 vs. 1.1 and 0.74$)$ and Jabal Mebreh (0.38 and -0.35 vs. 0.96 and 1.53). Despite the proximity of the Al Ain (Fig. 4b) and Jabal Hafeet (Fig. 4c) stations, the former's observed rainfall accumulations are magnified by approximately a factor of 2 . This is attributed to differing topography, with the difference in elevation reaching $957 \mathrm{~m}$ and the fact that the Jabal Hafeet rain gauge is situated on the lee side of the mountain with respect to the advection of the storm, whereas the $\mathrm{Al}$ Ain gauge is in an open desert terrain with no topographic obstructions.

\subsubsection{Station $2 \mathrm{~m}$ temperature versus WRF and WRF-WRF-Hydro}

Figure 5 shows the hourly observed and simulated WRF and WRF-WRF-Hydro $2 \mathrm{~m}$ temperature at the stations of Abu Dhabi (Fig. 5a), Al Ain (Fig. 5b), Jabal Hafeet (Fig. 5c), and Jabal Mebreh (Fig. 5d). Both WRF and WRF-WRF-Hydro show a strong warm bias across all four stations during the morning and day hours, with the higher biases occurring during the first day of the simulation (8 March 2016). Also, both models produced smaller cold biases during the night hours. The stations recorded a sharp decrease in temperature between 07:00 Z and 10:00 Z on 9 March 2016 which is temporally consistent with the associated rainfall initiation at each station in Fig. 4. Both simulations with WRF-WRFHydro and WRF reproduced the decline in temperature espe- cially at Abu Dhabi (Fig. 5a) and Al Ain stations (Fig. 5b). The decrease in temperature between 07:00 Z and 10:00 Z on 9 March 2016 at the mountain stations, namely, Jabal Hafeet (Fig. 5c) and Jabal Mebreh (Fig. 5d) was not significant. Overall, the difference between WRF-WRF-Hydro and WRF temperatures was more significant at $\mathrm{Al}$ Ain and Abu Dhabi stations than at the mountain stations. The decrease in temperature simulated by WRF-WRF-Hydro and WRF between 07:00 Z and 10:00 Z on 9 March 2016 preceded the decline in the observed temperatures, which is in line with the lag between simulated and observed rainfall, especially at the Abu Dhabi station, with simulated rainfall initiated earlier than the observed.

Figure 6 shows the scatterplot of the hourly $2 \mathrm{~m}$ temperature from the WRF and WRF-WRF-Hydro output fields against the temperature observations from all 57 stations in the network. The warm biases appear to increase with the rise in temperature, confirming the previously noted stronger daytime biases and its consistency at all stations.

Table 4 lists the statistical measures obtained from both simulations compared to the observed records. Slight improvement (below $1^{\circ} \mathrm{C}$ ) was achieved in the simulated range (min-max) and mean by the coupling. Similarly, minor improvements were recorded in the PCC (0.81 vs. 0.71), RMSE ( 1.56 vs. 1.61 ), and rBIAS (0.03 vs. 0.04 ). The morning overestimation of $2 \mathrm{~m}$ temperature can be attributed to the dual cooling effects of existing dust and/or aerosols and the strong land-sea breeze interactions noted by Lazzarini et al. (2014). Both factors are dominant over coastal and arid regions, such as the UAE and are not fully incorporated in the current model physics.

The increase in rainfall should have increased soil moisture and therefore led to an increase of the latent heat over the sensible heat, causing a decline in air temperature. The improvement of temperature simulation with WRF-Hydro over WRF could be attributed to the capability of WRF-Hydro to simulate soil moisture spatial distribution more reliably than WRF. Nevertheless, both models still show a warm bias. The heat exchange between land and atmosphere which controls the change in air temperature is site specific. It also depends on land cover conditions which defines the roughness length for heat and local topography (macro roughness and surface geometry) which defines the roughness length for momentum (Yang et al., 2008). This is also in combination with the soil moisture effect which impacts surface emissivity, surface temperature, and therefore the simulated air temperature. This explains the different behaviors of temperature at the different sites.

\subsubsection{Station global radiation versus WRF and WRF-WRF-Hydro}

Figure 7 shows the hourly observed and simulated WRF and WRF-WRF-Hydro global radiation at the stations of Abu Dhabi (Fig. 7a), Al Ain (Fig. 7b), Jabal Hafeet (Fig. 7c), and 
Table 4. The $2 \mathrm{~m}$ temperature statistical measures from collocated stations and simulation outputs.

\begin{tabular}{lrrrrrrr}
\hline $\begin{array}{l}2 \text { m temperature } \\
\text { source }\end{array}$ & $\begin{array}{r}\text { Mean } \\
\left({ }^{\circ} \mathrm{C}\right)\end{array}$ & $\begin{array}{r}\text { Min. } \\
\left({ }^{\circ} \mathrm{C}\right)\end{array}$ & $\begin{array}{r}\text { Max. } \\
\left({ }^{\circ} \mathrm{C}\right)\end{array}$ & $\begin{array}{l}\text { SD } \\
\left({ }^{\circ} \mathrm{C}\right)\end{array}$ & PCC & RMSE & rBias \\
\hline Station observations & 20.62 & 7.62 & 33.21 & 3.71 & & & \\
WRF & 22.63 & 8.91 & 35.62 & 4.64 & 0.77 & 1.61 & 0.04 \\
WRF-WRF-Hydro & 22.76 & 8.94 & 35.73 & 4.65 & 0.81 & 1.56 & 0.03 \\
\hline
\end{tabular}
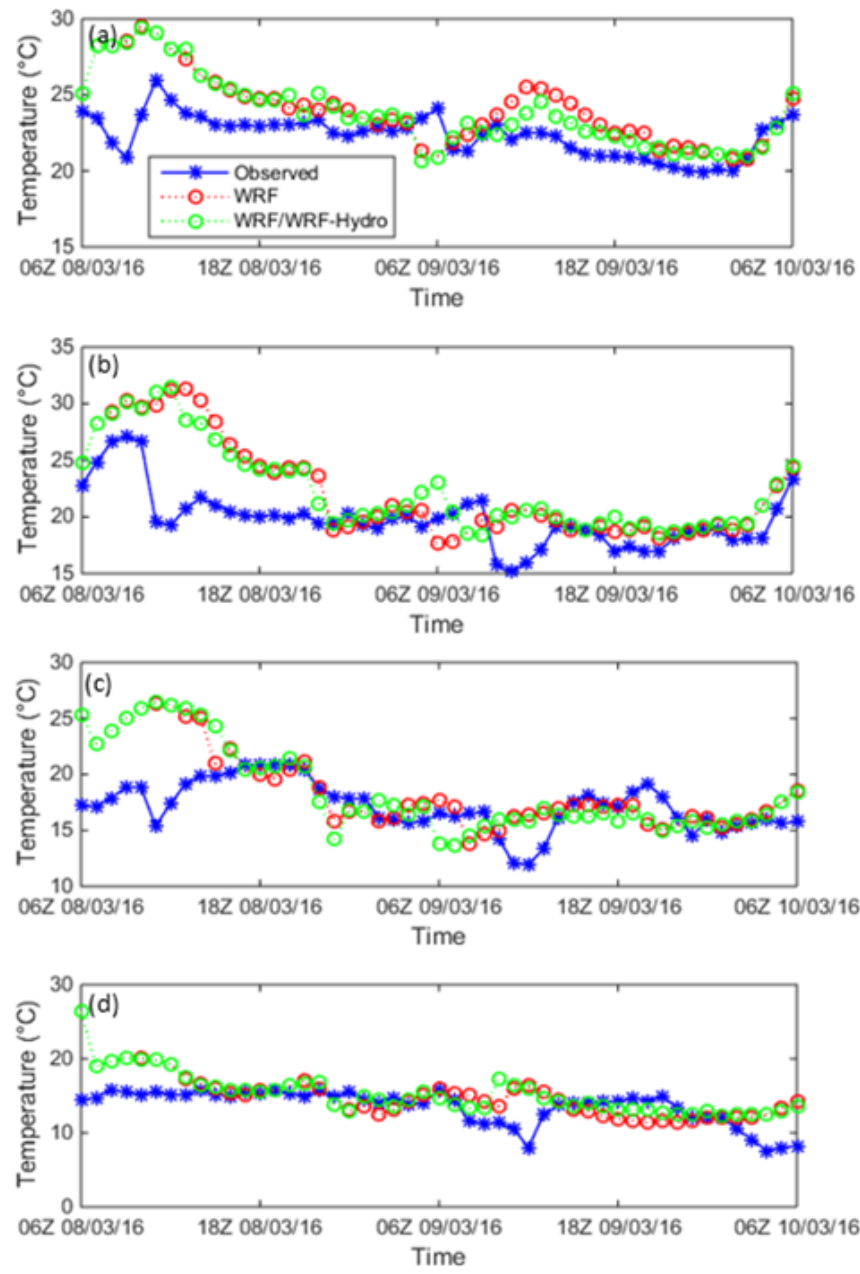

Figure 5. Comparison of $2 \mathrm{~m}$ temperature observations at $\mathrm{Abu}$ Dhabi (a), Al Ain (b), Jabal Hafeet (c), and Jabal Mebreh (d) stations with WRF and WRF-WRF-Hydro simulations.

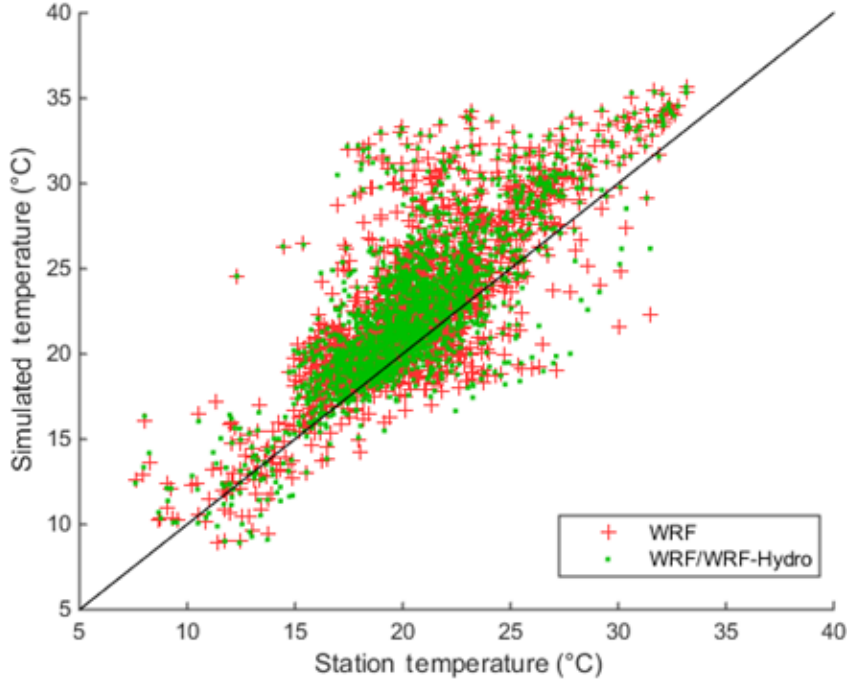

Figure 6. Scatterplot of $2 \mathrm{~m}$ temperature from WRF and WRFWRF-Hydro simulations versus station observations across the UAE.

Jabal Mebreh (Fig. 7d). Both WRF and WRF-WRF-Hydro show overestimations, especially for the Jabal Mebreh station, over the first day of the simulation (8 March 2016). Similar to the $2 \mathrm{~m}$ temperature warm bias evolution, the radiation overestimations are reduced in the second day of the simulation (9 March 2016). Also, the lower radiation readings during the second day are temporally consistent with the $2 \mathrm{~m}$ temperature depressions (Fig. 5) and rainfall initiation (Fig. 4) at each station. It was observed that the WRFWRF-Hydro simulation better matches the observed temporal variation and magnitudes than the WRF simulation.

Figure 8 shows the scatterplot of the global radiation from the WRF and WRF-WRF-Hydro simulations fields against the station observations. The WRF-WRF-Hydro radiation variability demonstrates much less deviation from the station observations compared to that of the WRF model.

Table 5 lists the statistical measures obtained from both simulations compared to the observed records. Higher agreement with the observed mean $\left(101.96 \mathrm{~W} \mathrm{~m}^{-2}\right)$ and maximum $\left(985.05 \mathrm{~W} \mathrm{~m}^{-2}\right)$ was achieved by the coupled simulation, with a mean of $112.68 \mathrm{~W} \mathrm{~m}^{-2}$ and a maximum of $805.12 \mathrm{~W} \mathrm{~m}^{-2}$, compared to the uncoupled simulation mean of $133.31 \mathrm{~W} \mathrm{~m}^{-2}$ and maximum of $788.16 \mathrm{~W} \mathrm{~m}^{-2}$. The 

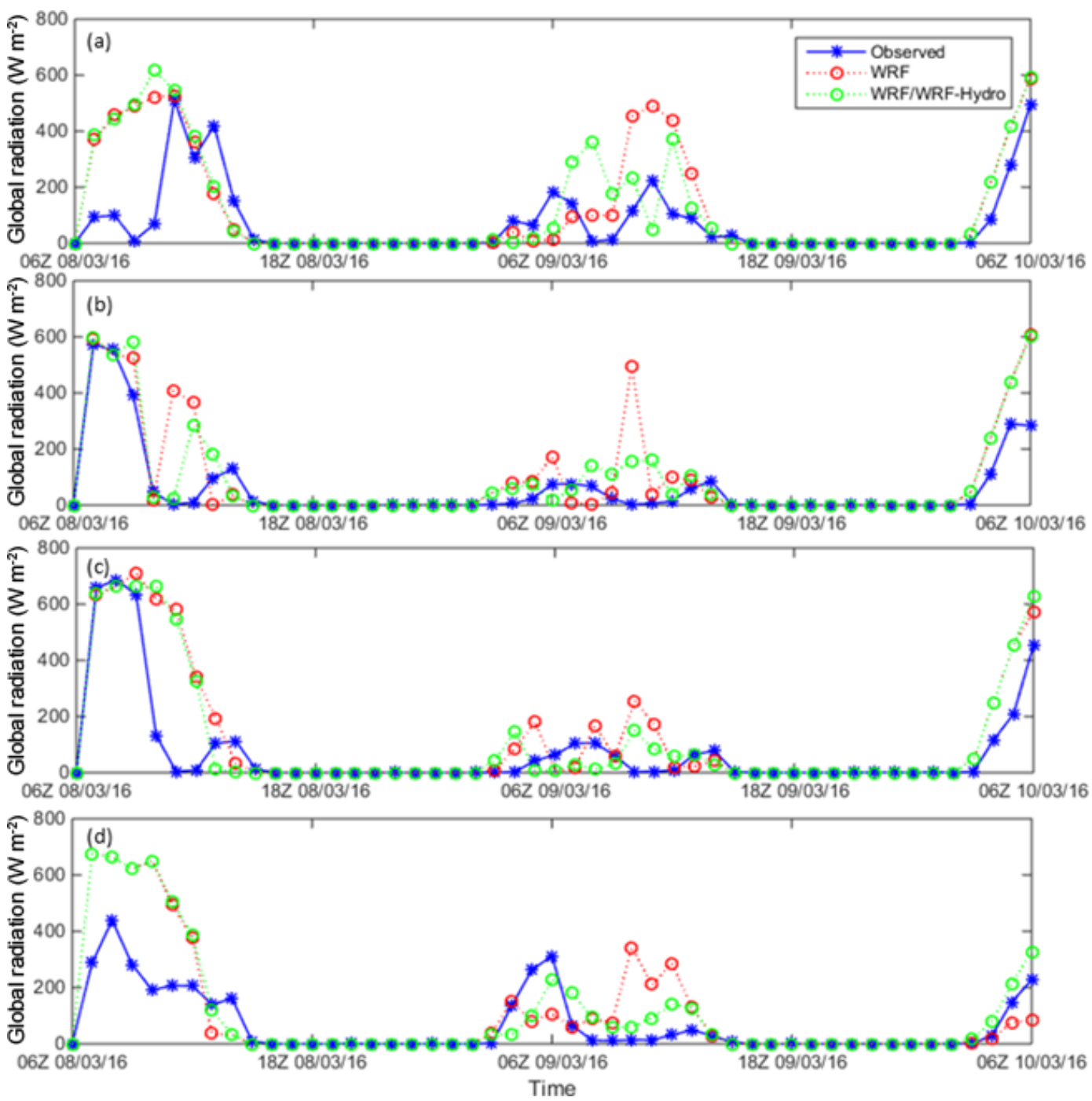

Figure 7. Comparison of global radiation observations at Abu Dhabi (a), Al Ain (b), Jabal Hafeet (c), and Jabal Mebreh (d) stations with WRF and WRF-WRF-Hydro simulations.

Table 5. Global radiation statistical measures from the stations and simulations at 15 min intervals $(n=194)$.

\begin{tabular}{lcccccrc}
\hline $\begin{array}{l}\text { Global radiation } \\
\text { Source }\end{array}$ & $\begin{array}{c}\text { Mean } \\
\left(\mathrm{W} \mathrm{m}^{-2}\right)\end{array}$ & $\begin{array}{c}\text { Min. } \\
\left(\mathrm{W} \mathrm{m}^{-2}\right)\end{array}$ & $\begin{array}{c}\text { Max. } \\
\left(\mathrm{W} \mathrm{m}^{-2}\right)\end{array}$ & $\begin{array}{c}\mathrm{SD} \\
\left(\mathrm{W} \mathrm{m}^{-2}\right)\end{array}$ & PCC & RMSE & rBIAS \\
\hline Station observations & 101.96 & 0 & 985.05 & 189.80 & & & \\
WRF & 133.31 & 0 & 788.16 & 214.70 & 0.78 & 139.61 & 0.33 \\
WRF-WRF-Hydro & 112.68 & 0 & 805.12 & 198.12 & 0.89 & 73.72 & 0.21 \\
\hline
\end{tabular}

coupling improvement is further corroborated by the PCC of 0.89 versus 0.78 , RSME of 73.72 versus 139.61, and rBIAS of 0.21 versus 0.33 . This is potentially explained by the lower day-night amplitude in surface temperature with WRF-Hydro, which, in turn, reduces the deviation in upward longwave radiation and net radiation.

Zempila et al. (2016) assessed the performance of different shortwave radiation schemes, namely the Dudhia, up- dated Goddard and the Goddard Fluid Dynamics Laboratory (GFDL), and RRTMG (used here). They compared the simulated global radiation to a set of hourly measurements at 12 stations over Greece. Overestimations between $40 \%$ and $70 \%$ were recorded for all schemes, while a better agreement was achieved during clear (cloudless) sky conditions. In the present study, improved bias results of $33 \%$ and $21 \%$ 


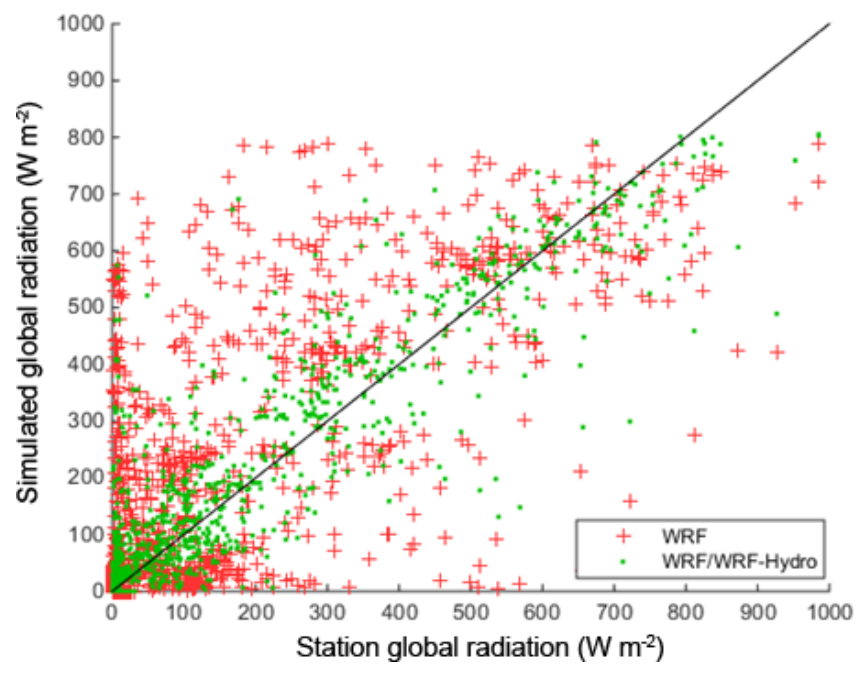

Figure 8. Scatterplot of global radiation from WRF and WRFWRF-Hydro simulations versus station observations across the UAE.

biases were obtained from WRF and WRF-WRF-Hydro, respectively (see Table 5).

Figure 9 shows the cumulative cloud fraction from the MODATM level-2 retrievals $(10 \mathrm{~km})$ and both the WRF and WRF-WRF-Hydro simulations $(1 \mathrm{~km})$ for 9 March 2016. The cloud fraction ranges from 0 (cloud-free) to 1 (complete cloud cover). The cloud base altitude was found to be in the range of $5 \mathrm{~km}$ from both MODATM, standalone WRF, and WRF-WRF-Hydro, which is also in line with the profiles of Fig. 2. Overall, the simulated cloud cover was reproduced to a much smaller extent, especially overland in the western coastal areas. Díaz et al. (2015) assessed the capability of the WRF model to reproduce clouds over the African region with varying configurations and physics options and their comparisons with satellite observations. They concluded an overall underestimation of cloud cover from their nine WRF simulations, particularly in the case of marine-boundary layer clouds over coastal areas. Their simulations resolved a high number of thick clouds and too few clouds with lower optical thickness. The net result was an underestimation of low cloud cover, which is the case of the present study. Otkin and Greenwald (2008) also examined the ability of WRF to reproduce cloud properties during an extratropical cyclone over the North Atlantic Ocean. Similar to the present study, they relied on MODATM retrievals for model verification with different combinations of cloud microphysics and PBL schemes, and found consistent underestimation. They attributed the underestimation to the utilization of radiance and reflectance data on a $1 \mathrm{~km}$ grid by MODATM, and therefore its ability to capture small cumulus clouds, whereas the WRF model horizontal resolution $(4 \mathrm{~km})$ failed to explicitly resolve all processes. This is not the case with the present study, given the matching $1 \mathrm{~km}$ horizontal resolution used for d03. Hence, model resolution is shown to be of less significance for cloud resolving, while focus should be placed on the inclusion of a cumulus parameterization (not explored here) which may improve the model simulations through a better representation of the subgrid-scale cumulus clouds within this region. It is also possible that MODATM overestimated cloud coverage over the study domain. It is known that in the presence of high reflective surfaces (high albedo) in the background, such as snow, ice, or desert, cloud products become less accurate (Kotarba, 2010).

As a key factor in land-atmosphere interactions, clouds directly impact the radiation balance in terms of the amount reflected, absorbed, and emitted, depending on various cloud physical properties. Therefore, the underestimation of cloud fraction in both model configurations explains the observed overestimation in simulated global radiation, with less reflectance and more radiation reaching the surface. Also, the underestimation of precipitation during the first $12 \mathrm{~h}$ (see Fig. 4) is primarily attributed to the models' spin-up time and GFS bias during initialization. This could be supported with Fig. 9 which shows an underestimation of cloud extent in the cases of both WRF and WRF-WRF-Hydro.

\subsection{Analyses of hydrological processes}

\subsubsection{WRF-Hydro soil moisture versus AMSR2 retrievals}

Figure 10 shows the soil moisture retrievals from ASMR2 $(10 \mathrm{~km})$, the standalone WRF (1-D Noah-MP $-1 \mathrm{~km})$, and the simulated WRF-WRF-Hydro $(100 \mathrm{~m})$ during 9 March 2016 at 00:00:00 and after the event at 00:45:00 on 10 March 2016. The increase in soil moisture from both model simulations along the coast and western desert areas after the event on 10 March 2016 at 00:45:00 verifies the anticipated soil exfiltration and runoff drainage direction from the northeastern mountains toward the western lowlands (see Fig. 1). The higher soil moisture values resulting from the WRF-WRF-Hydro simulation are primarily attributed to the increase in simulated precipitation compared to standalone WRF (see Fig. 3).

Figure 11 shows scatter plots of the soil moisture values from ASMR2 and WRF-WRF-Hydro from both timings after re-gridding at $10 \mathrm{~km}$ through least-squares interpolation. The spatial comparison of WRF-WRF-Hydro and AMSR2 soil moisture estimates revealed three increasing soil moisture classes: R1, R2, and R3 (delineated in Fig. 10) with an overall RMSE and rBIAS of 0.07 and $0.08(8 \%)$, respectively.

The region over the western part of the country (R1) received negligible rainfall (see Fig. 3), and consequently, recorded the lowest soil moisture value class ranging from 0 to $0.15 \mathrm{~m}^{3} \mathrm{~m}^{-3}$. Hence, the default USGS soil conditions and parameterization in the Noah-MP scheme remained unchanged, while showing the highest positive overestimation 

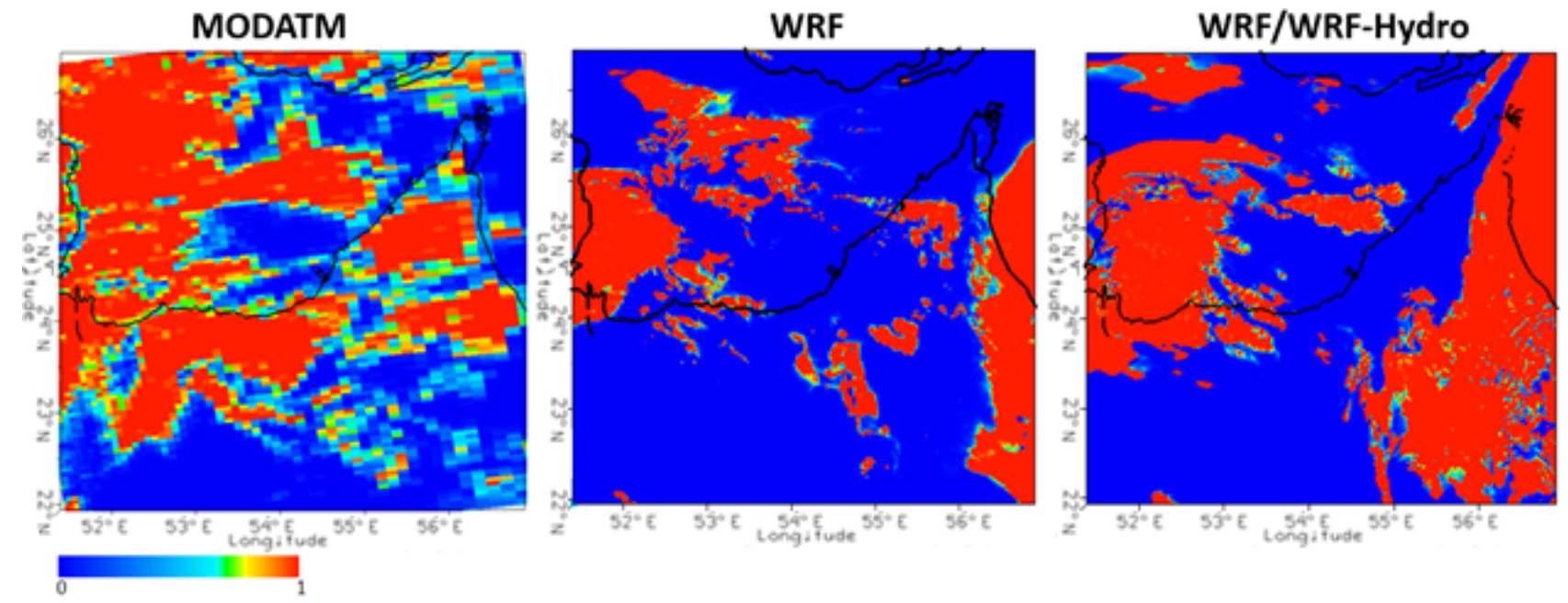

Figure 9. Cumulative cloud fraction retrieved from MODATM and simulated by WRF and WRF-WRF-Hydro for 9 March 2016

with an rBIAS of 0.64 . The second class of soil moisture values (R2), ranging from 0.15 to $0.25 \mathrm{~m}^{3} \mathrm{~m}^{-3}$, received light simulated rainfall between 30 to $70 \mathrm{~mm}$ (see Fig. 3). This class recorded the lowest positive rBIAS of 0.02 , which is attributed to the negating effect of the simulated rainfall underestimations on the existing positive initialization biases. Whereas the third class of soil moisture values (R3), ranging from 0.25 to $0.5 \mathrm{~m}^{3} \mathrm{~m}^{-3}$, recorded a negative bias of -0.18 . This can be explained by the combined effect of higher simulated rainfall underestimations and the topographical corrections incorporated in the AMSR2 product, resulting in outliers beyond $0.35 \mathrm{~m}^{3} \mathrm{~m}^{-3}$. The uncertainty of passive microwave retrievals over rough terrain has been recorded by several studies (Park et al., 2016; Zhan et al., 2015; Wang et al., 2010; Njoku and Chan, 2006). Moreover, the use of passive microwave $\mathrm{C}$ and $\mathrm{X}$ band frequencies in the retrieval of soil moisture should only reflect the effect of water content in the top $1 \mathrm{~cm}$ of soil as the penetration of the signal is limited, especially in the case of wet soils. This shallow measurement fails to match with the $10 \mathrm{~cm}$ depth of the first layer in WRF-Hydro (Ek et al., 2003). The increase of soil moisture in R2 and R3 implies that WRF-Hydro simulated the routing of the streamflow in wadis and the lateral flow of subsurface saturated soil. The increase could also be attributed to exfiltration from saturated soils of water flowing from the Hajar Mountain region towards lower lands in the western region. Recall that simulations were carried out in arid regions with ephemeral and ungauged rivers. In the absence of streamflow and/or water level measurements, the verification of the hydrological processes in this study relied on remotely sensed observations. We mainly relied on passive microwave retrievals of soil moisture, which are known to be more reliable and make use of well-established algorithms compared to other retrievals from active microwave or thermal satellite observations. Nevertheless, retrievals from pas- sive microwave observations are relatively coarse in terms of spatial resolution. They remain however relevant for regional assessments like the one conducted in this study.

\subsubsection{WRF-Hydro soil moisture propagation with lateral flow}

The Soil Moisture Operational Products System (SMOPS), provided by the National Oceanic and Atmospheric Administration (NOAA), merges soil moisture retrievals from multi-satellites or sensors to generate a global product at higher spatial and temporal coverage (Liu et al., 2016). Relevant to the current study period, SMOPS now incorporates near real-time SMAP data and includes soil moisture retrievals from the GPM Microwave Imager (GMI). The 6hourly product mapped at $0.25^{\circ}$ spatial resolution is used here to assess the accuracy of the simulated soil moisture.

A comparison of soil moisture evolution at the upstream and downstream of a wadi within the study domain is expected to verify whether soil moisture transport occurs over the storm timescale. A wadi within the coverage of the Saih Al Salem station $\left(24^{\prime} 49^{\prime \prime} 39^{\circ} \mathrm{N}, 55^{\prime} 18^{\prime \prime} 43^{\circ} \mathrm{E}\right)$ was selected to conduct this test. Figure 12 shows the time series of simulated soil moisture from WRF-WRF-Hydro at two locations upstream and downstream of the wadi. SMOPS retrievals are overlaid as data points, along with the hyetograph recorded at the corresponding Saih Al Salem station at the top. Given the short distance (less than $1 \mathrm{~km}$ ) separating the two locations, a lag time of less than $1 \mathrm{~h}$ is observed between the two soil moisture peaks. The first rain of approximately $22 \mathrm{~mm}$ at $22: 00 \mathrm{Z}$ on 8 March 2016 triggers an immediate increase in soil moisture from 0.18 to $0.25 \mathrm{~m}^{3} \mathrm{~m}^{-3}$. The subsequent rainfall then elevates the moisture further to around $0.34 \mathrm{~m}^{3} \mathrm{~m}^{-3}$, with a slight increase in the peak of downstream soil moisture compared to that of the upstream that could be attributed to additional lateral drainage. However, at 

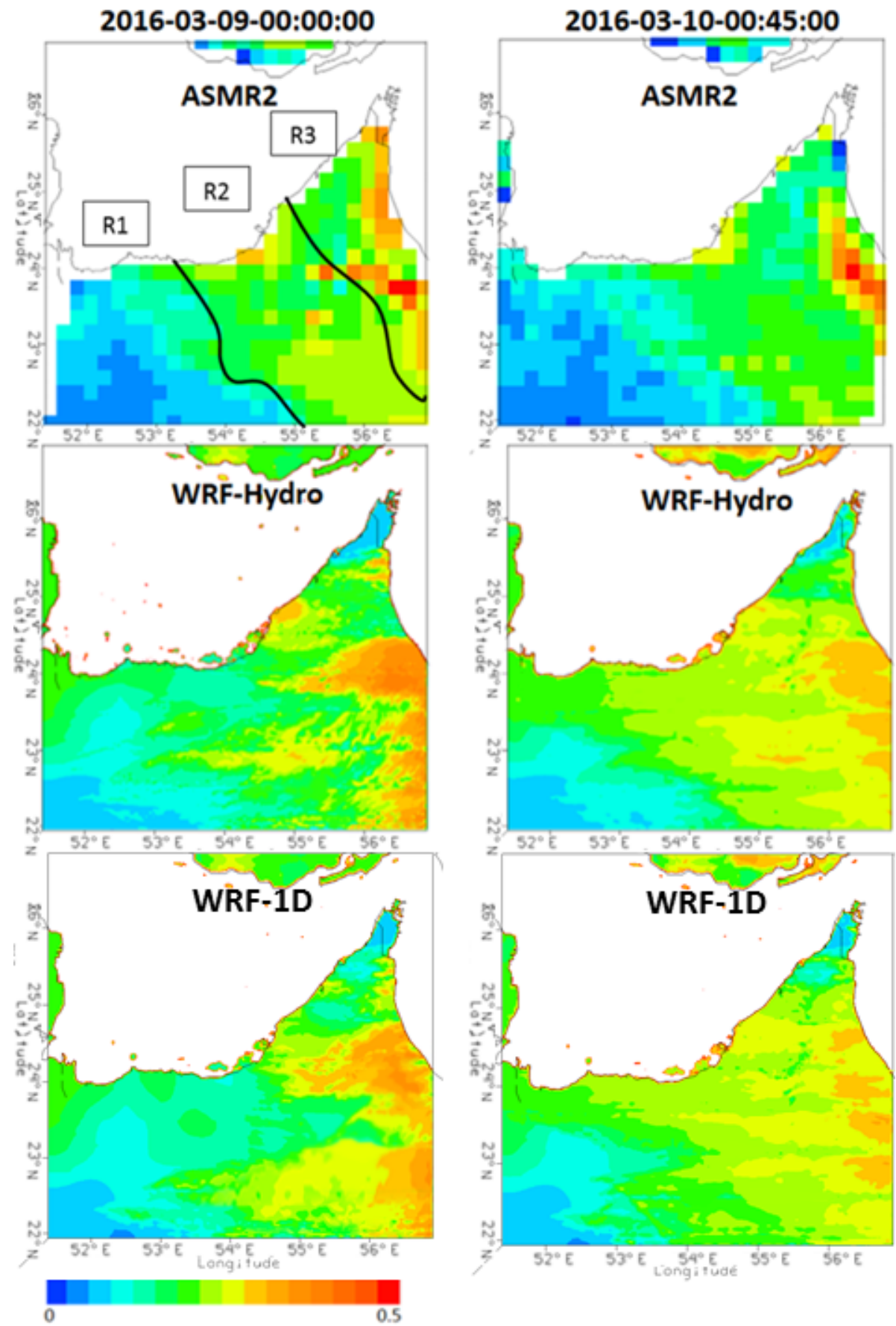

Figure 10. Comparison of simulated WRF-Hydro and retrieved AMSR2 soil moisture during (9 March 2016, 00:00:00) and after (10 March 2016, 00:45:00) the event.

18:00 Z on 9 March 2016 the downstream soil moisture rises again to a sustained peak at around $0.32 \mathrm{~m}^{3} \mathrm{~m}^{-3}$, while the upstream soil moisture continues to dissipate through infiltration and evaporation. In the absence of additional rainfall, this sustained peak in downstream soil moisture is the result of lateral surface flow from the upstream which is resolved by WRF-Hydro and fed back to the soil moisture fields. Despite the SMOPS data gaps during the event, the merged retrievals consistently increase during the event with reasonable accuracy compared to the simulated soil moisture fields. SMOPS data have a coarse spatial resolution that is an inherent limitation related to the resolution of the passive microwave signal, which does not allow verifying the drainage between the selected points. Nevertheless, the product captured the increase 

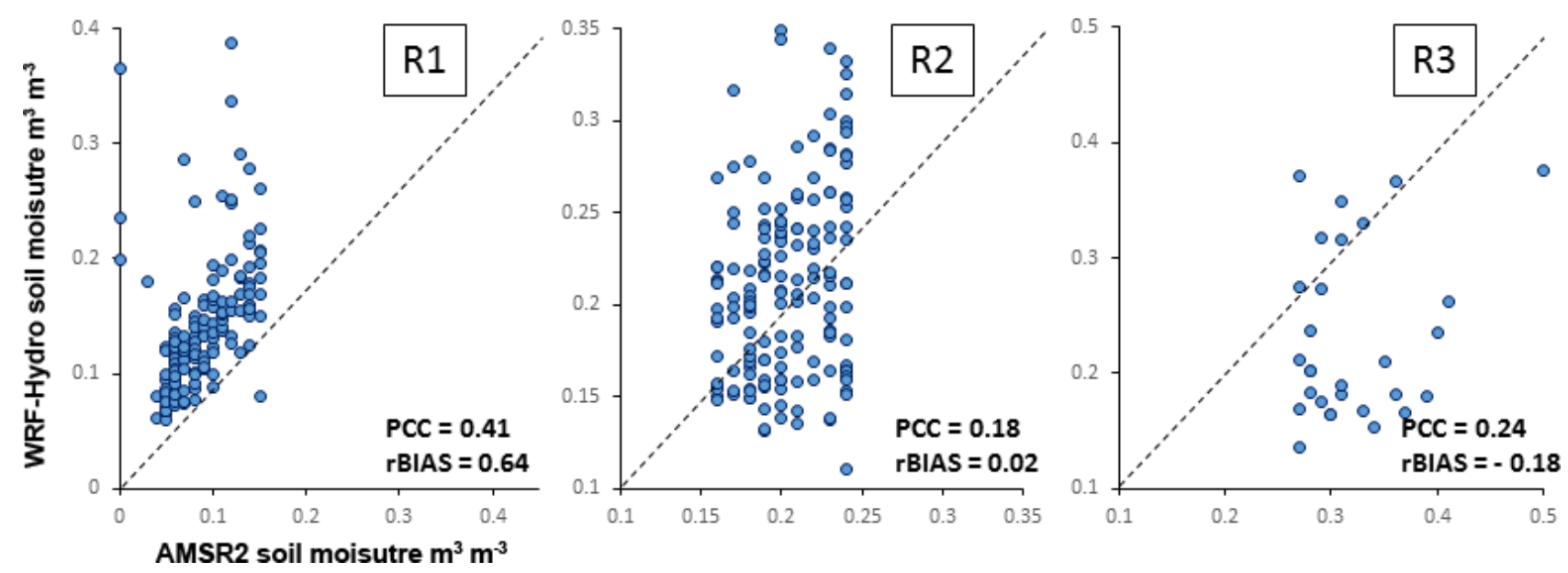

Figure 11. Scatterplots of AMSR2 and WRF-Hydro soil moisture estimates across the UAE.

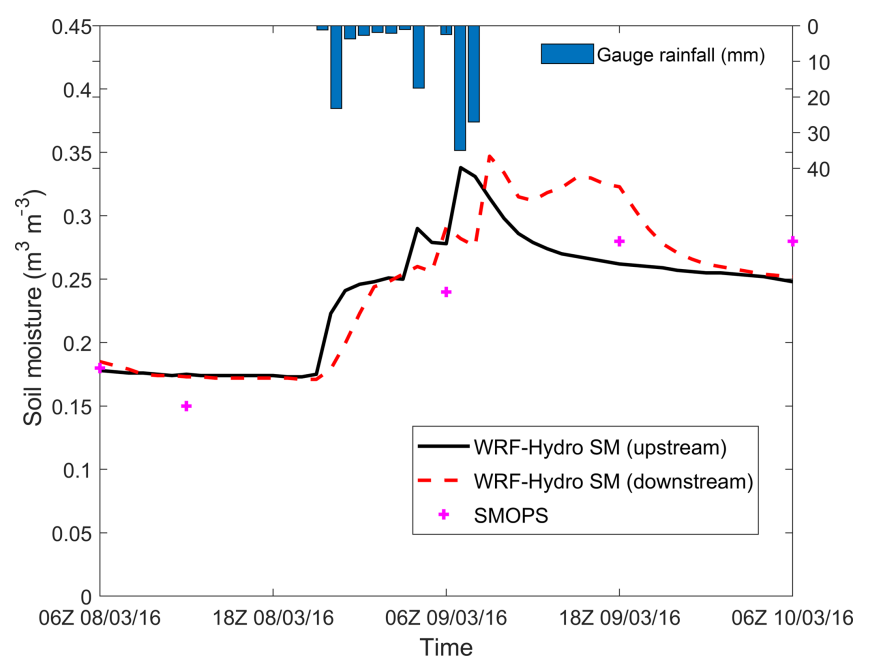

Figure 12. Time series of simulated soil moisture from WRFWRF-Hydro at wadi upstream and downstream locations, along with collocated SMOPS retrievals. The hyetograph recorded at the Saih Al Salem station is shown on top.

of moisture that is a result of the event and captured the persistent plateau of soil moisture after the event, which seem to be in a better agreement with WRF-Hydro values.

\subsubsection{Soil moisture-precipitation feedback}

An increase in water content of the top soil layer decreases both the surface albedo and the Bowen ratio. A lower surface albedo dictates more absorbance of net radiation, while lower Bowen ratios are a result of higher water vapor content in the boundary layer and more downwards flux of terrestrial radiation at the surface due to the water vapor greenhouse effect. This dual effect amounts to a larger total flux of heat from the surface into the boundary layer (Eltahir, 1998). Furthermore, the cooling of surface temperature accompanied by the moisture should be associated with a reduced sensible heat flux and a smaller PBL height. Figure 13 shows the PBL heights from both simulations with larger collapses resolved from the coupled model. According to Seidel et al. (2010), PBL heights can be inferred from radiosonde data (Fig. 2), particularly based on determining maximum or minimum vertical gradients of relative humidity or specific humidity. Such methods yield better agreement compared to those relying on locations of elevated temperature inversions or mixing height. Hence, using the Abu Dhabi radiosonde profile of Fig. 2, and basing on the gradient approach, the PBL height can be estimated to be in the range of $90-200 \mathrm{~m}$ at 12:00 Z, which is closer to that simulated from the coupled WRFWRF-Hydro (190 m) compared to standalone WRF (750 m).

Similar to the present study, Xiang et al. (2017) used the coupled WRF-Hydro system for short-term (72 h) simulations of storm events to discretize the effects of higher soil moisture conditions on precipitation generation, using the framework proposed by Eltahir (1998) to diagnose mechanisms of positive soil moisture-precipitation feedback. They captured an increase of up to $26 \mathrm{~mm}$ in WRF-WRF-Hydro precipitation over $48 \mathrm{~h}$, which is in line with the present study with a maximum increase of $23 \mathrm{~mm}$.

Koster et al. (2004) identified regional hot spots, including the Arabian peninsula, and particularly the UAE, where a global initialization of soil moisture may enhance precipitation prediction skill during summer in the Northern Hemisphere. Assuming predominantly local soil moisture impacts, the hot spots indicate where regular monitoring of soil moisture using in situ and satellite observation may lead to an enhancement in boreal summer seasonal forecasting. Their study also referred to a main challenge related to the dependency of the models on soil moisture computational estimates, and especially that a long spin up period might be required to reproduce reliable soil moisture values for seasonal forecasting. Senatore et al. (2015) showed that simulations 


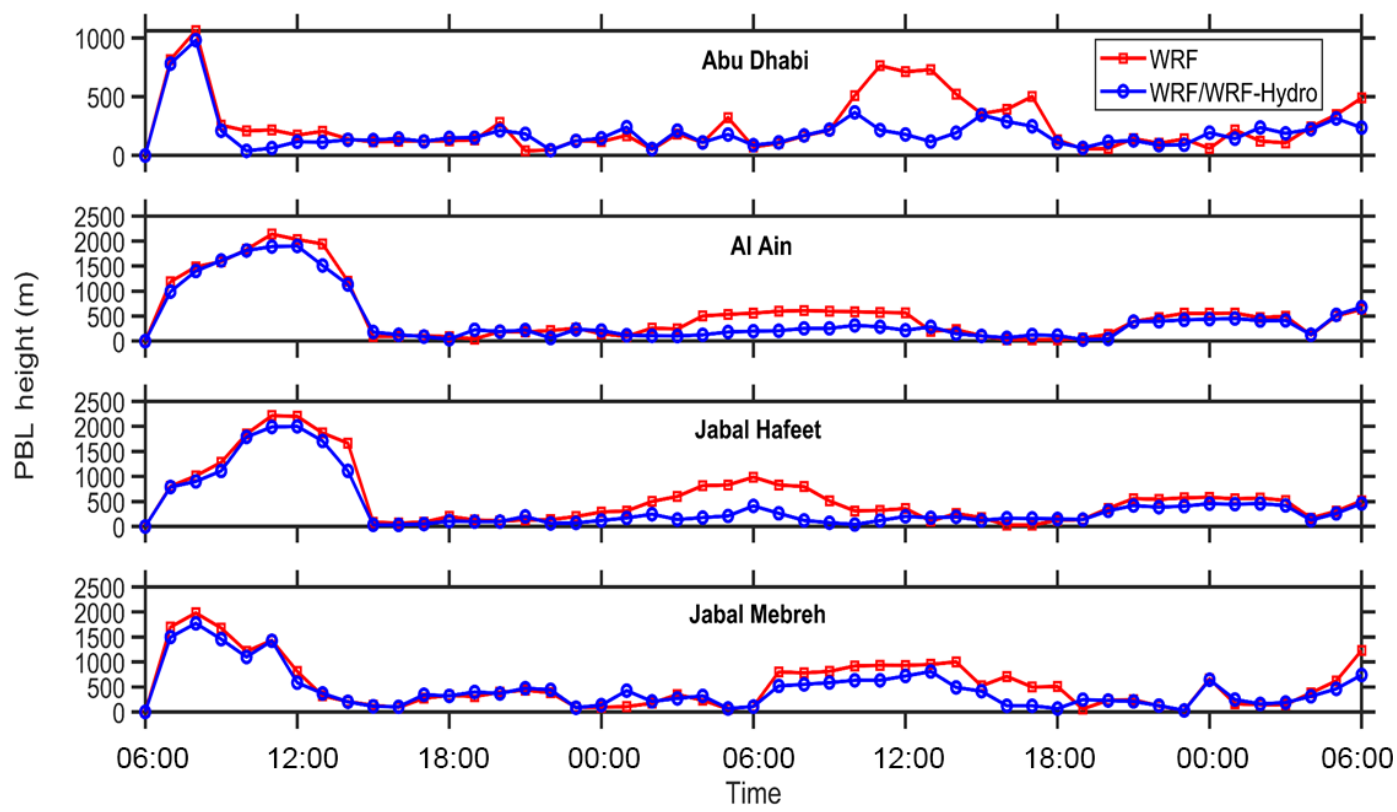

Figure 13. Planetary boundary layer (PBL) heights from WRF and WRF-WRF-Hydro simulations at each of the four stations.

for one month in a watershed in Italy required a 2-month spin up period. This fosters the importance of deploying dense soil moisture monitoring networks in the region (AlJassar et al., 2015; Temimi et al., 2014; Fares et al., 2013) which should contribute to a better understanding and characterization of soil moisture variability and hydrological processes in desert and hyper-arid environments. The description of routing and lateral flow by WRF-Hydro improved the quality of the simulated atmospheric processes in this case study. This promises improved seasonal precipitation forecasts, as well as short-term predictions assessed here.

\section{Conclusions}

In this study, we simulated an extreme weather event in March 2016 over the UAE, a country within the Arabian peninsula of particular interest for hydrometeorological research and monitoring. The event was simulated from both standalone WRF and fully coupled WRF-WRF-Hydro model configurations and compared to station observations and ongoing satellite products. The main objective of the study was to investigate the added value of coupled land surface-atmospheric modeling for precipitation forecasts over the hyper-arid environment of the UAE, while employing current modeling tools to aid in operational forecasting efforts in the region.

Results showed reductions of $24 \%$ and $13 \%$ in RMSE and rBIAS measures, respectively, for precipitation forecasts from the coupled model configuration. Furthermore, the coupled WRF-WRF-Hydro system was found to outperform GPM rainfall retrievals at some stations (e.g., Abu Dhabi and
Jabal Mebreh). The demonstrated improvement in coupled precipitation simulation, at the local scale, greatly enhances the accuracy of hydrologic forecasts and flash flood guidance systems. Senatore et al. (2015) explained the higher precipitation with their WRF-WRF-Hydro simulation by the differences in surface temperatures as a warmer surface boundary condition may lead to more convection and therefore higher energy and rainfall. The same interpretation could be also adopted in this study. The lateral boundary conditions are expected to severely restrict our model during these short $48 \mathrm{~h}$ simulations, however internal model variability is a direct consequence of the non-linear dynamical and physical internal processes being active and detectable (Christensen et al., 2001). However, despite the more skillful forecasts of the coupled system, the bias remains high ( $21 \%$ ), which dictates the need for ongoing hydrometeorological forecast enhancement.

The coupled system also showed improvements in global radiation forecasts $(45 \%$ and $12 \%$ for RMSE and rBIAS, respectively), while less significant enhancements were observed in the case of surface temperature $(3.1 \%$ and $1 \%)$. Both parameters were subject to high positive biases during the morning and daytime. The warm temperature biases were attributed to dry biases in the NCEP-GFS boundary conditions observed by Chaouch et al. (2017) and Yang et al. (2011) and the uncaptured cooling mechanisms of aerosols and sea breezes, while the underestimation of cloud cover explained the overestimations in global radiation. The diurnal temperature signal was not captured, even in the observed values, due to the extreme event. Also, the discrepancies in temperature simulations could be caused by soil moisture simulation and its spatial organization within the study 
domain which impacts the latent heat, the heat exchange, and therefore the temperature difference. More importantly, higher spin up times ( $6 \mathrm{~h}$ used here) can add to the model accuracy in terms of both atmospheric dynamics and hydrological processes (Lo et al., 2008). Soil moisture validation a challenging application over arid regions - showed varying response classes across the UAE and were consistent with the expected surface flow directions. The difference of spatial scales between the retrieved and simulated soil moisture, and the impact of high reflectance from desert land cover on the AMSR2 microwave retrieval algorithms may have contributed to the observed discrepancies (Wehbe et al., 2018).

The fully coupled model configuration captures the complete dynamics of the water and energy cycles, starting from the upper atmosphere to the unsaturated and saturated zones on the land surface and back. Land surface-atmospheric interactions are primarily governed by two key hydrological parameters, namely rainfall and soil moisture. Hence, future work with in situ soil moisture data assimilation is expected to enhance the model accuracy, both overland and in the atmosphere, through the captured feedbacks. This case study focused on a regional event triggered by a large-scale system. Hence, the impact of accounting for hydrological processes through the online coupling is not expected to be significant. Nevertheless, an improvement in the simulation of precipitation was obtained with the coupled WRF-WRF-Hydro model. To further discretize the added value of the coupling demonstrated in this study, ensemble approaches should be the focus of future work in order to assess the robustness of the potential improvements with WRF-Hydro. In the present study, the exact contribution of lateral flow versus internal atmospheric variability on the captured improvement remains an open question that is subject to further research in this area, particularly for arid environments that have not been receiving much attention.

Data availability. The GPM data are provided by the NASA's Goddard Space Flight Center and archived at the Goddard Earth Sciences Data and Information Services Center (GES DISC) (https: //disc.gsfc.nasa.gov/, GES DISC, 2018). The AMSR2 data are produced by Remote Sensing Systems and sponsored by the NASA AMSR-E Science Team and the NASA Earth Science MEaSUREs Program (http://www.remss.com/missions/amsr/, REMSS, 2018). The NCEP-GFS research data are archived at the National Center for Atmospheric Research (NCAR), Computational and Information Systems Laboratory, Boulder, Colorado (https://rda.ucar.edu/, NCAR, 2018). The MODATM product can be retrieved from the online data pool, courtesy of the NASA EOSDIS Land Processes Distributed Active Archive Center (LP DAAC), USGS Earth Resources Observation and Science (EROS) Center, Sioux Falls, South Dakota (https://lpdaac.usgs.gov/, NASA and USGS, 2018). The ground-based observations are obtained from the UAE National Center of Meteorology (NCM), which were provided under an agreement with clauses for non-disclosure of data. Access to these data are restricted and readers must request it through contacting research@ncms.ae.

Author contributions. MT and YW conceived and designed the case study. YW performed the simulations, postprocessing, and data analyses. YW and MT analyzed the results and wrote the article. MW, NC, OB, and TS advised on compiling and configuring the model in coupled mode. VW reviewed the results and revised the article. XZ and JL provided the NOAA SMOPS data and reviewed results. AA ensured quality control of the weather station observations.

Competing interests. The authors declare that they have no conflict of interest.

Acknowledgements. The authors acknowledge Khalifa University of Science and Technology (KUST) for the provided support. The authors would also like to thank the UAE National Center of Meteorology (NCM) for the quality-controlled weather station observations used in this study. The authors thank the NCM executive director, Abdulla Al Mandous, and program director, Alya Al Mazroui, for their continued support.

Financial support. This research has been supported by the Khalifa University of Science and Technology (grant no. SSG2015000060). This work was also conducted within the framework of a project funded by the NCM under the UAE Research Program for Rain Enhancement Science (UAEREP).

Review statement. This paper was edited by Gregor C. Leckebusch and reviewed by Nir Krakauer and one anonymous referee.

\section{References}

Ackerman, S. A., Strabala, K. I., Menzel, W. P., Frey, R. A., Moeller, C. C., and Gumley, L. E.: Discriminating clear sky from clouds with MODIS, J. Geophys. Res., 103, 32141-132157, 1998.

AlJassar, H. K., Petrov, P., Entekhabi, D., Temimi, M., Kodiyan, N., and Ansari, M.: Preliminary field results of soil moisture from Kuwait desert as a core validation site of SMAP satellite, Geoscience and Remote Sensing Symposium (IGARSS), 2015 IEEE International, 972-975, 2015.

Almazroui, M., Islam, M. N., Jones, P., Athar, H., and Rahman, M. A.: Recent climate change in the Arabian Peninsula: seasonal rainfall and temperature climatology of Saudi Arabia for 19792009, Atmos. Res., 111, 29-45, 2012.

AlSarmi, S. and Washington, R.: Recent observed climate change over the Arabian Peninsula, J. Geophys. Res.-Atmos., 116, D11109, 15 pp., 2011.

Argüeso, D., Hidalgo-Muñoz, J. M., Gámiz-Fortis, S. R., EstebanParra, M. J., Dudhia, J., and Castro-Díez, Y.: Evaluation of WRF 
parameterizations for climate studies over Southern Spain using a multistep regionalization, J. Clim., 24, 5633-5651, 2011.

Arnault, J., Wagner, S., Rummler, T., Fersch, B., Bliefernicht, J., Andresen, S., and Kunstmann, H.: Role of runoff-infiltration partitioning and resolved overland flow on land-atmosphere feedbacks: A case study with the WRF-Hydro coupled modeling system for west africa, J. Hydrometeorol., 17, 1489-1516, 2016.

Awad, A. K. A., Ajjaji, R., and Dhanhani, A.: Automatic two-way nested WRF Middle-East numerical weather forecast application, WRF user's workshop, National Center for Atmospheric Research, Boulder, CO, USA, 2007.

Benesty, J., Chen, J., Huang, Y., and Cohen, I.: Pearson correlation coefficient, in: Noise reduction in speech processing, Springer, $1-4,2009$.

Blašković, T.: Severe weather hits UAE and Oman: thunderstorms, large hail and severe flooding, The Watchers - Daily news service, Watchers.NEWS, available at: https://watchers.news/2016/03/09/severe-weather-hits-uaeand-oman-thunderstorms-large-hail-and-severe-flooding/ (last access: 15 January 2018), 9 March 2016.

Chaouch, N., Temimi, M., Weston, M., and Ghedira, H.: Sensitivity of the meteorological model WRF-ARW to planetary boundary layer schemes during fog conditions in a coastal arid region, Atmos. Res., 187, 106-127, 2017.

Christensen, O., Gaertner, M., Prego, J., and Polcher, J.: Internal variability of regional climate models, Clim. Dynam., 17, 875887,2001

Díaz, J., González, A., Expósito, F., Pérez, J., Fernández, J., GarcíaDíez, M., and Taima, D.: WRF multi-physics simulation of clouds in the African region, Q. J. Roy. Meteor. Soc., 141, $2737-$ $2749,2015$.

Ek, M., Mitchell, K., Lin, Y., Rogers, E., Grunmann, P., Koren, V., Gayno, G., and Tarpley, J.: Implementation of Noah land surface model advances in the National Centers for Environmental Prediction operational mesoscale Eta model, J. Geophys. Res.Atmos., 108, 8851, 16 pp., 2003.

El Afandi, G., Morsy, M., and El Hussieny, F.: Heavy rainfall simulation over sinai peninsula using the weather research and forecasting model, Int. J. Atmos. Sci., 2013, 241050, 11 pp., 2013.

Eltahir, E. A.: A soil moisture-rainfall feedback mechanism: 1. Theory and observations, Water Resour. Res., 34, 765-776, 1998.

Fang, H. Y., Cai, Q. G., Chen, H., and Li, Q. Y.: Mechanism of formation of physical soil crust in desert soils treated with straw checkerboards, Soil Till. Res., 93, 222-230, 2007.

Fares, A., Temimi, M., Morgan, K., and Kelleners, T. J.: In-situ and remote soil moisture sensing technologies for vadose zone hydrology, Vadose Zone J., 12, 1-3, 2013.

Fekete, B. M., Vörösmarty, C. J., Roads, J. O., and Willmott, C. $\mathrm{J} .:$ Uncertainties in precipitation and their impacts on runoff estimates, J. Clim., 17, 294-304, 2004.

Fiori, E., Comellas, A., Molini, L., Rebora, N., Siccardi, F., Gochis, D., Tanelli, S., and Parodi, A.: Analysis and hindcast simulations of an extreme rainfall event in the Mediterranean area: The Genoa 2011 case, Atmos. Res., 138, 13-29, 2014.

GES DISC: GPM_3IMERGDL.05, available at: https://disc.gsfc. nasa.gov/, last access: 15 January 2018.
Ghebreyesus, D. T., Temimi, M., Fares, A., and Bayabil, H. K.: A Multi-Satellite Approach for Water Storage Monitoring in an Arid Watershed, Geosciences, 6, 1-14, 2016a.

Ghebreyesus, D. T., Temimi, M., Fares, A., and Bayabil, H. K.: Remote Sensing Applications for Monitoring Water Resources in the UAE Using Lake Zakher as a Water Storage Gauge, in: Emerging Issues in Groundwater Resources, Springer, 145-157, 2016b.

Givati, A., Lynn, B., Liu, Y., and Rimmer, A.: Using the WRF model in an operational streamflow forecast system for the Jordan River, J. Appl. Meteorol. Clim., 51, 285-299, 2011.

Givati, A., Gochis, D., Rummler, T., and Kunstmann, H.: Comparing One-Way and Two-Way Coupled Hydrometeorological Forecasting Systems for Flood Forecasting in the Mediterranean Region, Hydrology, 3, 1-21, 2016

Gochis, D. and Sampson, K.: WRF Hydro GIS Pre-Processing Tools: Version 2.2 Documentation, National Center for Atmospheric Research, Research Applications Laboratory, Boulder, Colorado, 39, 1-44, 2015.

Gochis, D. J., Yu, W., and Yates, D. N.: The WRF-Hydro model technical description and user's guide, version 1.0, Ncar technical document, National Center for Atmospheric Research, Boulder, CO, USA, 120 pp., 2013.

Gochis, D., Yu, W., Sampson, K., Dugger, A., McCreight, J., Zhang, Y., and Ikeda, K.: Multi-scale model analysis and hindcast of the 2013 Colorado Flood, EGU General Assembly Conference Abstracts, EGU General Assembly, Vienna, Austria, 12 17 April 2015, 7531, 2015.

Hariprasad, K., Srinivas, C., Singh, A. B., Rao, S. V. B., Baskaran, R., and Venkatraman, B.: Numerical simulation and intercomparison of boundary layer structure with different PBL schemes in WRF using experimental observations at a tropical site, Atmos. Res., 145, 27-44, 2014.

Hu, X.-M., Nielsen-Gammon, J. W., and Zhang, F.: Evaluation of three planetary boundary layer schemes in the WRF model, J. Appl. Meteorol. Clim., 49, 1831-1844, 2010.

Huffman, G. J., Bolvin, D. T., Nelkin, E. J., Wolff, D. B., Adler, R. F., Gu, G., Hong, Y., Bowman, K. P., and Stocker, E. F.: The TRMM multisatellite precipitation analysis (TMPA): Quasiglobal, multiyear, combined-sensor precipitation estimates at fine scales, J. Hydrometeorol., 8, 38-55, 2007.

Huffman, G. J., Bolvin, D. T., Braithwaite, D., Hsu, K., Joyce, R., and Xie, P.: NASA Global Precipitation Measurement (GPM) Integrated Multi-satellitE Retrievals for GPM (IMERG), NASA Report, 1-35, 2014.

Iacono, M. J., Delamere, J. S., Mlawer, E. J., Shephard, M. W., Clough, S. A., and Collins, W. D.: Radiative forcing by longlived greenhouse gases: Calculations with the AER radiative transfer models, J. Geophys. Res.-Atmos., 113, D13103, 8 pp., 2008.

Koster, R. D., Dirmeyer, P. A., Guo, Z., Bonan, G., Chan, E., Cox, P., Gordon, C., Kanae, S., Kowalczyk, E., and Lawrence, D.: Regions of strong coupling between soil moisture and precipitation, Science, 305, 1138-1140, 2004.

Kotarba, A. Z.: Estimation of fractional cloud cover for Moderate Resolution Imaging Spectroradiometer/Terra cloud mask classes with high-resolution over ocean ASTER observations, J. Geophys. Res.-Atmos., 115, D22210, 11 pp., 2010. 
Larsen, M. A., Christensen, J. H., Drews, M., Butts, M. B., and Refsgaard, J. C.: Local control on precipitation in a fully coupled climate-hydrology model, Sci. Rep., 6, 22927 , https://doi.org/10.1038/srep22927, 2016.

Lazzarini, M., Marpu, P. R., Eissa, Y., and Ghedira, H.: Toward a near real-time product of air temperature maps from satellite data and in situ measurements in arid environments, IEEE J. Sel. Top. Appl., 7, 3093-3104, 2014.

Liu, J., Zhan, X., Hain, C., Yin, J., Fang, L., Li, Z., and Zhao, L.: NOAA Soil Moisture Operational Product System (SMOPS) and its validations, IEEE International Geoscience and Remote Sensing Symposium (IGARSS), 10-15 July 2016, Beijing, China, https://doi.org/10.1109/IGARSS.2016.7729899, 2016.

Lo, J. C. F., Yang, Z. L., and Pielke, R. A.: Assessment of three dynamical climate downscaling methods using the Weather Research and Forecasting (WRF) model, J. Geophys. Res.-Atmos., 113, D09112, 16 pp., 2008.

Mandoos, A.: Synoptic and atmospheric stability classification for the United Arab Emirates, Msc. Thesis, Johannesburg, University of the Witwatersrand, 2006.

Milewski, A., Elkadiri, R., and Durham, M.: Assessment and comparison of tmpa satellite precipitation products in varying climatic and topographic regimes in morocco, Remote Sens., 7, 5697-5717, 2015.

Mlawer, E. J., Taubman, S. J., Brown, P. D., Iacono, M. J., and Clough, S. A.: Radiative transfer for inhomogeneous atmospheres: RRTM, a validated correlated-k model for the longwave, J. Geophys. Res.-Atmos., 102, 16663-16682, 1997.

Monin, A. and Obukhov, A.: Basic laws of turbulent mixing in the surface layer of the atmosphere, Contrib. Geophys. Inst. Acad. Sci. USSR, 151, 163-187, 1954.

Morrison, H., Thompson, G., and Tatarskii, V.: Impact of cloud microphysics on the development of trailing stratiform precipitation in a simulated squall line: Comparison of one-and two-moment schemes, Mon. Weather Rev., 137, 991-1007, 2009.

NASA and USGS: MODIS/Terra Joint Cloud, Aerosol, Water Vapour and Profile, available at: https://lpdaac.usgs.gov/, last access: 15 January 2018.

NCAR: NCEP GFS Model Analysis and Forecast, available at: https://rda.ucar.edu/, last access: 15 January 2018.

Nielsen-Gammon, J. W., Zhang, F., Odins, A. M., and Myoung, B.: Extreme rainfall in Texas: Patterns and predictability, Phys. Geogr., 26, 340-364, 2005.

Niu, G. Y.: The Community NOAH Land-surface Model (LSM) with Multi-physics Options, Tech. rep., National Centers for Environmental Prediction (NCEP), Oregon State University, Air Force, and Hydrology Lab-NWS, https://www.jsg.utexas.edu/ noah-mp/users-guide/ (last access: 2 February 2017), 2011.

Niu, G. Y., Yang, Z. L., Mitchell, K. E., Chen, F., Ek, M. B., Barlage, M., Kumar, A., Manning, K., Niyogi, D., and Rosero, E.: The community Noah land surface model with multiparameterization options (Noah-MP): 1. Model description and evaluation with local-scale measurements, J. Geophys. Res.-Atmos., 116, D12109, 19 pp., 2011.

Njoku, E. G. and Chan, S. K.: Vegetation and surface roughness effects on AMSR-E land observations, Remote Sens. Environ., 100, 190-199, 2006.
Otkin, J. A. and Greenwald, T. J.: Comparison of WRF modelsimulated and MODIS-derived cloud data, Mon. Weather Rev., 136, 1957-1970, 2008.

Ouarda, T., Charron, C., Kumar, K. N., Marpu, P., Ghedira, H., Molini, A., and Khayal, I.: Evolution of the rainfall regime in the United Arab Emirates, J. Hydrol., 514, 258-270, 2014.

Park, N.-W., Hong, S., Kyriakidis, P. C., Lee, W., and Lyu, S.-J.: Geostatistical downscaling of AMSR2 precipitation with COMS infrared observations, Int. J. Remote Sens., 37, 3858-3869, 2016.

Parodi, A., Hooper, R., Jha, S., and Zaslavsky, I.: Advancing hydrometeorological prediction capabilities through standardsbased cyberinfrastructure development: The community WRFHydro modeling system, EGU General Assembly Conference Abstracts, Vienna, Austria, 7-12 April 2013, EGU2013-6011, 2013.

Platnick, S., Ackerman, S., King, M., Meyer, K., Menzel, W., Holz, R., Baum, B., and Yang, P.: MODIS atmosphere L2 cloud product (06_L2), NASA MODIS Adaptive Processing System, Goddard Space Flight Center, 10, 1-53, 2015.

Powers, J. G., Klemp, J. B., Skamarock, W. C., Davis, C. A., Dudhia, J., Gill, D. O., Coen, J. L., Gochis, D. J., Ahmadov, R., and Peckham, S. E.: The weather research and forecasting model: Overview, system efforts, and future directions, B. Am. Meteorol. Soc., 98, 1717-1737, 2017.

Read, L.: Street Level Hydrology: An Urban Application of the WRF-Hydro Framework in Denver, Colorado, AGU Fall Meeting, American Geophysical Union Fall Meeting, 14-18 December 2015, San Francisco, California, USA, H51I-1499, 2015.

REMSS: AMSR2/AMSRE, available at: http://www.remss.com/ missions/amsr/, last access: 15 January 2018.

Sathiyamoorthy, V., Mahesh, C., Gopalan, K., Prakash, S., Shukla, B. P., and Mathur, A.: Characteristics of low clouds over the Arabian Sea, J. Geophys. Res.-Atmos., 118, 13489-13503, 2013.

Seidel, D. J., Ao, C. O., and Li, K.: Estimating climatological planetary boundary layer heights from radiosonde observations: Comparison of methods and uncertainty analysis, J. Geophys. Res.Atmos., 115, 16 pp., 2010.

Senatore, A., Mendicino, G., Gochis, D. J., Yu, W., Yates, D. N., and Kunstmann, H.: Fully coupled atmosphere-hydrology simulations for the central Mediterranean: Impact of enhanced hydrological parameterization for short and long time scales, J. Adv. Model. Earth Sy., 7, 1693-1715, 2015.

Shin, H. H. and Hong, S.-Y.: Intercomparison of planetary boundary-layer parametrizations in the WRF model for a single day from CASES-99, Bound.-Lay. Meteorol., 139, 261-281, 2011.

Silver, M., Karnieli, A., Ginat, H., Meiri, E., and Fredj, E.: An innovative method for determining hydrological calibration parameters for the WRF-Hydro model in arid regions, Environ. Modell. Softw., 91, 47-69, 2017.

Skamarock, W. C., Klemp, J. B., Dudhia, J., Gill, D. O., Barker, D. M., Wang, W., and Powers, J. G.: A description of the advanced research WRF version 2, DTIC Document, 1-101, 2005.

Smart, J. R., Shaw, B. L., and McCaslin, P.: WRF SI V2. 0 : Nesting and details of terrain processing. Technical Report, NOAA Forecast Systems Laboratory, Boulder, Colorado, available at: http://sgi200.ust.hk/mm5/workshop/ws04/Session6/ Smart.John.pdf (last access: 15 January 2018), 2005. 
Tarboton, D. G., Bras, R. L., and Rodriguez-Iturbe, I.: On the extraction of channel networks from digital elevation data, Hydrol. Process., 5, 81-100, 1991.

Temimi, M., Lakhankar, T., Zhan, X., Cosh, M. H., Krakauer, N., Fares, A., Kelly, V., Khanbilvardi, R., and Kumassi, L.: Soil moisture retrieval using ground-based L-band passive microwave observations in northeastern USA, Vadose Zone J., 13, 15 pp., 2014

Toutin, T.: ASTER DEMs for geomatic and geoscientific applications: a review, Int. J. Remote Sens., 29, 1855-1875, 2008.

Tsvieli, Y. and Zangvil, A.: Synoptic climatological analysis of Red Sea Trough and non-Red Sea Trough rain situations over Israel, Adv. Geosci., 12, 137-143, 2007.

Unal, E.: Modeling the Colorado Front Range Flood of 2013 with Coupled WRF and WRF-Hydro System, AGU Fall Meeting, American Geophysical Union Fall Meeting, 14-18 December 2015, San Francisco, California, USA, H51E-1413, 2015.

Wang, P., Jiang, L., Zhang, L., and Guo, Y.: Impact of terrain topography on retrieval of snow water equivalence using passive microwave remote sensing, Geoscience and Remote Sensing Symposium (IGARSS), 2010 IEEE International, 1757-1760, 2010.

Wang, W. and Seaman, N. L.: A comparison study of convective parameterization schemes in a mesoscale model, Mon. Weather Rev., 125, 252-278, 1997.

Wehbe, Y., Ghebreyesus, D., Temimi, M., Milewski, A., and Al Mandous, A.: Assessment of the consistency among global precipitation products over the United Arab Emirates, J. Hydrol., 12, 122-135, 2017.

Wehbe, Y., Temimi, M., Ghebreyesus, D. T., Milewski, A., Norouzi, H., and Ibrahim, E.: Consistency of precipitation products over the Arabian Peninsula and interactions with soil moisture and water storage, Hydrol. Sci. J., 63, 408-425, 2018.
Wentz, F., Meissner, T., Gentemann, C., Hilburn, K., and Scott, J.: Remote sensing systems GCOM-W1 AMSR2 daily environmental suite on 0.25 deg grid Version 7.2, 2014.

Xiang, T., Vivoni, E. R., and Gochis, D. J.: Influence of initial soil moisture and vegetation conditions on monsoon precipitation events in northwest México, Atmósfera, 31, 25-45, 2017.

Yang, K., Koike, T., Ishikawa, H., Kim, J., Li, X., Liu, H., Liu, S., Ma, Y., and Wang, J.: Turbulent flux transfer over bare-soil surfaces: characteristics and parameterization, J. Appl. Meteorol. Climatol., 47, 276-290, 2008.

Yang, Z. L., Niu, G. Y., Mitchell, K. E., Chen, F., Ek, M. B., Barlage, M., Longuevergne, L., Manning, K., Niyogi, D., and Tewari, M.: The community Noah land surface model with multiparameterization options (Noah-MP): 2. Evaluation over global river basins, J. Geophys. Res.-Atmos., 116, D12110, 16 pp., 2011.

Yousef, L. A. and Ouarda, T.: Adaptation of Water Resources Management to Changing Climate: The Role of Intensity-DurationFrequency Curves, Int. J. Environ. Sci. Dev., 6, 478-483, 2015.

Yucel, I., Onen, A., Yilmaz, K., and Gochis, D.: Calibration and evaluation of a flood forecasting system: Utility of numerical weather prediction model, data assimilation and satellite-based rainfall, J. Hydrol., 523, 49-66, 2015.

Zempila, M.-M., Giannaros, T. M., Bais, A., Melas, D., and Kazantzidis, A.: Evaluation of WRF shortwave radiation parameterizations in predicting Global Horizontal Irradiance in Greece, Renew. Energ., 86, 831-840, 2016.

Zhan, W., Pan, M., Wanders, N., and Wood, E.: Correction of realtime satellite precipitation with satellite soil moisture observations, Hydrol. Earth Syst. Sc., 19, 4275-4291, 2015. 